Fisheries Research

July 2017, Volume 191 Pages 131-143

http://dx.doi.org/10.1016/i.fishres.2017.03.010

http://archimer.ifremer.fr/doc/00376/48766/

(c) 2017 Elsevier B.V. All rights reserved.

\title{
A Bayesian two-stage biomass model for stock assessment of data-limited species: An application to cuttlefish (Sepia officinalis) in the English Channel
}

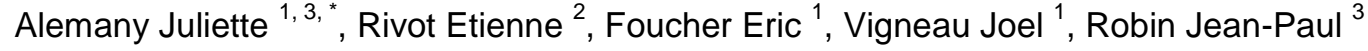 \\ ${ }^{1}$ Ifremer, Port-en-Bessin, France \\ 2 UMR 985 ESE Ecology and Ecosystem Health, Agrocampus Ouest, INRA, 35042 Rennes, France \\ ${ }^{3}$ Research Unit BOREA "Biology of Aquatic Organisms and Ecosystems", University of Caen, \\ Normandy, France \\ *Corresponding author : Juliette Alemany, email addresses : juliette.alemany@ifremer.fr ; \\ juliette.alemany@gmail.com
}

\begin{abstract}
:
Cuttlefish is a key commercial species in the English Channel fishery in terms of landings and value. Age-based assessment methods are limited by time-consuming age determination with statoliths and the lack of stock assessment models tailored to this data-limited species. A two-stage biomass model is developed in the Bayesian state-space modelling framework that allows inferences to be made on the stock biomass at the start, middle and end of each fishing seasons between 1992 and 2014, while accounting for both process and measurement errors and to assimilate various sources of information. A method that uses ancillary length-frequency data is developed to provide an informative prior distribution for the biomass growth rate parameter $g(E=0.89)$ and its annual variability $(C V=0.1)$. The new model is a substantial improvement on the existing stock assessment method used by the International Council for the Exploration of the Seas. Taking into consideration a time-varying $g$ parameter provides a more ecologically meaningful model with regard to the sensitivity of the cuttlefish population dynamics to environmental fluctuations and improves model fit. The model also provides predictions of the unexploited biomass in winter, which is based on survey data, and helps manage the stock in the event of strong depletion.
\end{abstract}

Keywords : English Channel, Cuttlefish, Sepia officinalis, Bayesian state-space model, Data-limited stock, Two-stage biomass model 


\section{Introduction}

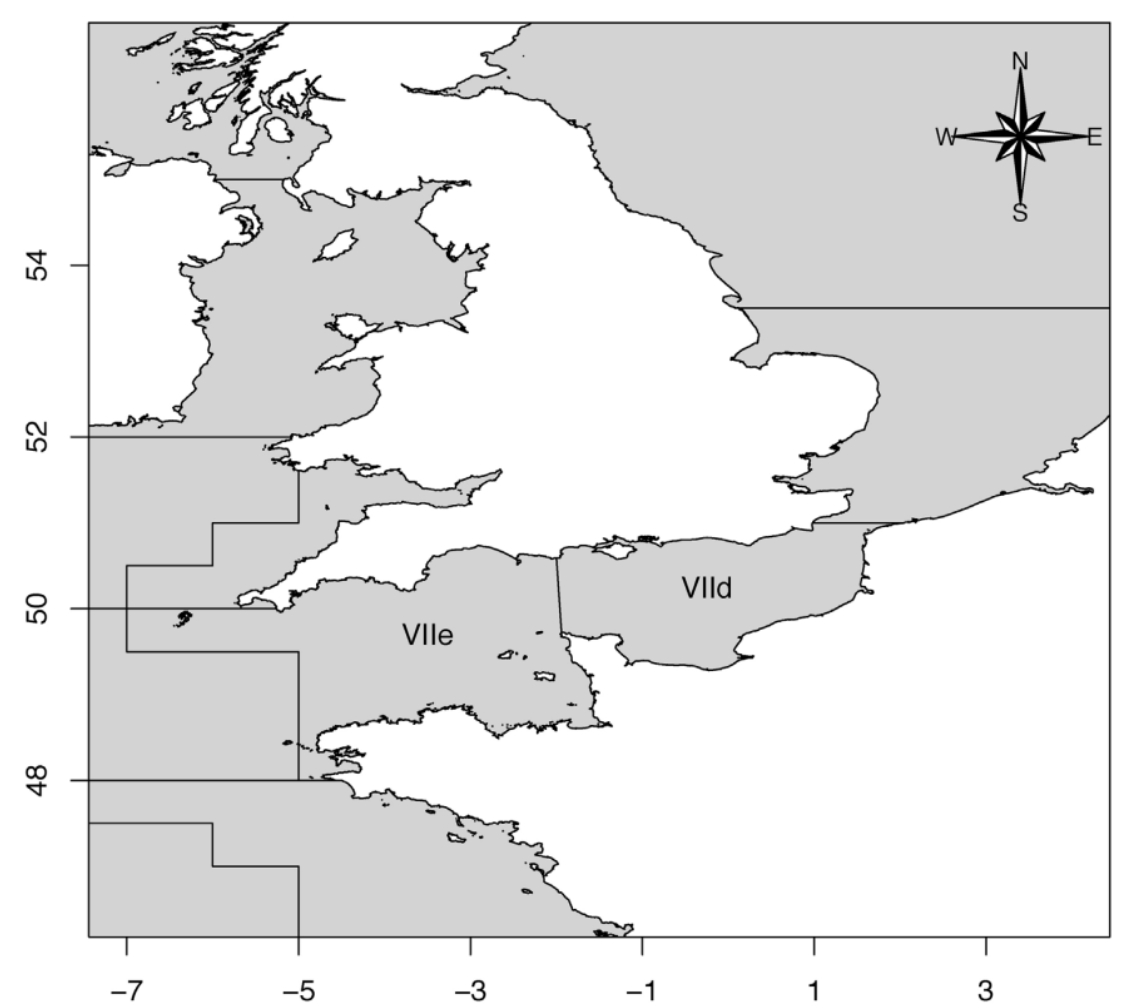

Fig. 1. Location of the stock studied. The English Channel is composed of ICES divisions VIId and VIIe.

Cephalopods stocks are difficult to assess and require specific models to be developed (Pierce and Guerra, 1994) because of the nature of their life cycle, including short life span and highly variable growth, and because of the difficulty of age determination (Bettencourt and Guerra, 2001; González et al., 2000; Lipinski et al., 1998). The lack of routine stock assessment methods for short-lived species restricts sharing of information and comparing status among stocks, and reinforces the need for a precautionary approach (Rodhouse et al., 2014).

The cuttlefish stock in the English Channel (Fig. 1) is data-limited. This stock is assumed to be a single unit because of high catch-per-unit-effort concentration in International Council for the Exploration of the Seas (ICES) divisions VIId and VIIe (Wang, 2003). It is a shared resource exploited by French and English fishermen (Engelhard et al., 2012). No European regulations apply to this stock despite its importance in terms of landings and value. The French inshore exploitation is managed by local rules such as minimum landing weight and mesh size. In England, no minimum landing size and no restrictions on the fishing season have been established for cuttlefish (Pierce et al., 2010).

The English Channel cuttlefish population is semelparous with a two-year lifespan. Migration outside the Channel is suspected to be very low (Boucaud-Camou and Boismery, 1991). Adults spawn inshore in shallow waters in spring and die. Hatching peaks in summer, and juveniles stay inshore until autumn. Recruitment into the fishery starts in October of the first year, and the annual cohort is fully recruited at the start of the second summer of life, i.e. one year after hatching. Tagging experiments have shown inshore-offshore seasonal migrations: cuttlefish concentrate offshore in the deeper central western part of the Channel during winter, and move inshore in spring for coastal feeding and spawning (Boucaud- 
Camou and Boismery, 1991). Seasonal migrations are mainly triggered by temperature, although day-length also influences pre-adult sexual maturation (Richard, 1971).

The stock has been assessed using a Thomson and Bell model based on monthly catchat-age data (Royer et al., 2006), but the method, based on monthly length frequencies, was too data-demanding for a routine stock assessment. Furthermore, conversion of length frequencies into age is highly uncertain because growth and timing of migration might vary substantially according to seasons and years. A much less data demanding two-stage biomass model (Roel and Butterworth, 2000) was proposed for this stock (Gras et al., 2014). The model developed by Gras et al. (2014) represents the biomass of group 1+ individuals only, and assumes two stages among the exploited population: recruitment and full exploitation. Recruited biomass ( $B_{1}$; evaluated on the first of July) is estimated using abundance indices from the Bottom Trawl survey (BTS) and the Channel Ground Fish Survey (CGFS). Spawning stock biomass $\left(B_{2}\right)$ is then estimated using Landings Per Unit Effort (LPUE) from French and United Kingdom (UK) bottom trawl fisheries. The model is fitted to the time series of catches and abundance indices using a maximum likelihood framework that assumes observation errors only, and uncertainties about estimates are quantified using bootstrapping. The model suffers from several weaknesses. Firstly, it considers observation errors only and hence ignores process errors in the biomass dynamics. It also suffers from a lack of flexibility to change model assumptions and/or to assimilate other sources of available information or data. Secondly, the growth rate parameter $g$ (between 12 and 23 months old cuttlefish) is assumed to be known and constant from year to year even though the growth rate of cephalopods is known to be highly sensitive to environmental fluctuations (Rodhouse et al., 2014). The parameter $g$ includes natural mortality (set to 1.2 year $^{-1}$ ) and a mean growth rate in weight (based on historical data from Medhioub (1986) and set to $2.2 \mathrm{yr}^{-}$ ${ }^{1}$ ), which are assumed to be constant in time and known without uncertainty. However, Gras et al. (2014) showed a high sensitivity of model outputs to the growth rate parameter, and advocated the use of more recent data that would provide a more accurate estimate of this parameter. Thirdly, the model only captures the dynamics of the $1+$ component of the population. The time series of abundance indices from the CGFS survey is assumed to be based mainly on group 1+ individuals, although length frequencies suggest a mixture of $0+$ and 1+. Indeed, the CGFS survey occurs in October, when cuttlefish migrate offshore. Some of the group 0 individuals are 3 months old at this time of the year and form the lower part of the survey length frequencies. Therefore, using the CGFS time series without processing the data to separate out the two cohorts might provide a biased estimate of group 1+ cuttlefish biomass.

In this work, we have perfected the two-stage biomass model adapted for cuttlefish, based on three substantive new contributions:

(a) The model is developed in a Bayesian state-space framework (Rivot et al., 2004; Buckland et al., 2007; Parent and Rivot, 2013), thus allowing for a comprehensive integration of the different sources of uncertainty by considering both process errors in the biomass dynamics and observation error in the data.

(b) We develop an informative prior (Hilborn and Liermann, 1998) on the biomass growth rate that takes advantage of various sources of available data to quantify the average growth rate and provide a credible range of variability over the years.

(c) We improve the quality of the data and the demographic realism of the model by explicitly considering that two separate age classes $(0+$ and $1+)$ can compose the abundance indices and the exploited biomass.

We first build a model considering the dynamics of 1+ only and a time-varying $g$ parameter. We then evaluate the benefit of a time-varying $g$ parameter instead and evaluate the sensitivity of the results to the amount of data used and the predictive capacity of the 
model. Finally, we explore the feasibility of considering the dynamics of the two cohorts $(0+$ and $1+$ ) in the same model.

\section{Materials and methods}

We first describe the data used for stock assessment and provide details about the data processing. Then we detail the process equations for the biomass dynamics and the observation equations. Thirdly, we detail the method used to construct an informative prior distribution on the biomass growth rate parameter (denoted $g_{0, \mathrm{y}}$ and $g_{1, \mathrm{y}}$ for 0 and $1+$ groups respectively). Finally, we outline our strategy to analyze the sensitivity of the results to the hypotheses about between-year variation of critical parameters, to the age-structure and the data sources. All parameters used in the model are summarized in Table 1, and variants of the baseline model are summarized in Table 2 .

Table 1

The priors.

\begin{tabular}{|c|c|c|c|}
\hline & Parameter & Description & Distribution \\
\hline & $\mu_{\mathrm{B} 1}$ & Grand mean of $B_{1, y}$ & $\operatorname{Lognormal}(\mu=15000, C V=0.1)$ \\
\hline & $\sigma_{B 1}^{2}$ & Variance of $B_{1, y}$ & InverseGamma $(0.05,0.05)$ \\
\hline & $\mu_{g_{1}}$ & Grand mean of $g_{1, y}$ & $\begin{array}{l}\operatorname{Lognormal}(\mu=0.89 \\
\qquad \mathrm{CV}=0.1)\end{array}$ \\
\hline & $\sigma_{g 1}^{2}$ & Variance of $g_{l, y}$ & InverseGamma $(0.05,0.05)$ \\
\hline & $\mathrm{E}_{1, \mathrm{y}}$ & Exploitation rate for group $1+$ & $\operatorname{Beta}(\alpha=1.5, \beta=1.5)$ \\
\hline & $C V_{\text {process }}$ & $\begin{array}{c}\mathrm{CV} \text { used for the lognormal process } \\
\text { errors }\end{array}$ & Exponential $(\lambda=6)$ \\
\hline & $C V_{C 1}$ & $\mathrm{CV}$ used for the catch of group $1+$ & $\operatorname{Exponential}(\lambda=8)$ \\
\hline & $\log \left(q_{b t s}\right)$ & Catchability of the BTS survey & Uniform $(\mathrm{a}=-15, \mathrm{~b}=3)$ \\
\hline & $\log \left(\mathrm{q}_{\mathrm{cgfs}}\right)$ & Catchability of the CGFS survey & $\operatorname{Uniform}(\mathrm{a}=-15, \mathrm{~b}=3)$ \\
\hline & $\log \left(q_{\text {lpuel }}\right)$ & $\begin{array}{c}\text { Catchability of the group } 1+\text { French } \\
\text { LPUE }\end{array}$ & $\operatorname{Uniform}(\mathrm{a}=-15, \mathrm{~b}=3)$ \\
\hline & $\sigma_{b t s}^{2}$ & $\begin{array}{c}\text { Variance of observation errors for BTS } \\
\text { survey }\end{array}$ & InverseGamma $(0.05,0.05)$ \\
\hline & $\sigma_{c g f s}^{2}$ & $\begin{array}{c}\text { Variance of observation errors for } \\
\text { CGFS survey }\end{array}$ & InverseGamma $(0.05,0.05)$ \\
\hline & $\sigma_{\text {lpue } 1}^{2}$ & $\begin{array}{l}\text { Variance of observation errors for } \\
\text { group 1+ French LPUE }\end{array}$ & InverseGamma $(0.05,0.05)$ \\
\hline \multirow{8}{*}{ 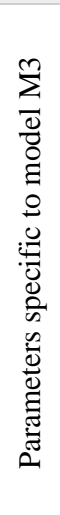 } & $\mu_{\mathrm{B} 0}$ & Grand mean of $B_{0, y}$ & $\operatorname{Lognormal}(\mu=5000, \mathrm{CV}=0.5)$ \\
\hline & $\mu_{g_{0}}$ & Grand mean of $\mathrm{g}_{0, \mathrm{y}}$ & $\begin{array}{l}\operatorname{Lognormal}(\mu=0.97 \\
\qquad \mathrm{CV}=0.1)\end{array}$ \\
\hline & $\mathrm{E}_{0, \mathrm{y}}$ & Exploitation rate for group 0 & $\operatorname{Beta}(1.5,1.5)$ \\
\hline & $\log \left(q_{\text {lpue } 0}\right)$ & $\begin{array}{l}\text { Catchability of the French LPUE for } \\
\text { group } 0\end{array}$ & Uniform(-15, 3) \\
\hline & $\sigma_{B 0}^{2}$ & Variance of $\mathrm{B}_{0, \mathrm{y}}$ & InverseGamma $(0.05,0.05)$ \\
\hline & $\sigma_{g 0}^{2}$ & Variance of $g_{0, y}$ & InverseGamma $(0.05,0.05)$ \\
\hline & $C V_{C 0}$ & $\begin{array}{l}\mathrm{CV} \text { of observation errors for group } 0 \\
\text { catches }\end{array}$ & $\operatorname{Exponential}(\lambda=8)$ \\
\hline & $\sigma_{\text {lpue } 0}^{2}$ & $\begin{array}{l}\text { Variance of observation errors for the } \\
\text { group } 0 \text { French LPUE }\end{array}$ & InverseGamma $(0.05,0.05)$ \\
\hline
\end{tabular}


Table 2

Model hypotheses.

\begin{tabular}{llll}
\hline Model & Exploited biomass & $\boldsymbol{g}$ parameter & Abundance indices used \\
\hline M1 & Group $1+$ only & Time-varying $\left(\mathrm{g}_{1, \mathrm{y}}\right)$ & BTS, CGFS, LPUE $(1+)$ \\
M2 & Group $1+$ only & Fixed $\left(\mathrm{g}_{1}\right)$ & BTS, CGFS, LPUE $(1+)$ \\
M3 & Group 0 and $1+$ & Time-varying $\left(\mathrm{g}_{0, \mathrm{y}}\right.$ and $\left.\mathrm{g}_{1, \mathrm{y}}\right)$ & BTS, CGFS, LPUE $(1+)$, LPUE $(0)$ \\
M4 & Group $1+$ only & Time-varying $\left(\mathrm{g}_{1, \mathrm{y}}\right)$ & BTS, CGFS \\
\hline
\end{tabular}

\subsection{Data sources and data processing}

We used total catch data from the English and French fisheries, and abundance indices from the English BTS and French CGFS surveys, with additional information to separate group 0 and group 1+ animals. The BTS abundance indices and UK catch and effort data were obtained from the Center for Environment Fisheries and Aquaculture Science (CEFAS). The French CGFS abundance indices, French catch and effort, and length data were obtained from the French Research Institute for Exploitation of the Sea (IFREMER). BTS abundance indices were used to model the biomass of 1+ age group only. This group of 0 individuals represents a very small proportion of the BTS survey data because the survey occurs around July just after hatchlings are born, and because the research vessel does not fish too close to the coast where juveniles are found (Carpentier et al., 2009). BTS abundance indices were calculated as catch-per-unit-effort, using trawling time as effort, and scaled so that the first value of the time series equals 1.

The CGFS survey data were used to provide indices of abundance for the $0+$ and $1+$ age groups. The CGFS occurs each year during October (Coppin et al., 2002). Some cuttlefish of the group 0 are already 3 months old at this time of the year and are potentially caught during the CGFS. The following procedure was used to separate the two cohorts $(0$ and $1+)$ and to provide a more reliable abundance index for the 1+ group only. The package mixdist (Macdonald et al., 2011) was applied to the CGFS length frequency data to calculate the mean length and the percentage of number of individuals older than one year-old $\left(\% N_{1+, y}\right)$ for each fishing season $y$ (Appendix A). Mean length was converted into mean weight using the Dunn (1999a) length-weight relationship. Percentage in weight of group 1+ individuals was calculated as follows:

$$
\% w_{1+, \mathrm{y}}=\left[\% N_{1+, \mathrm{y}} * \bar{w}_{1+, \mathrm{y}}\right] /\left[\bar{w}_{1+, \mathrm{y}} * \% N_{1+, \mathrm{y}}+\bar{w}_{0, \mathrm{y}} *\left(1-\% N_{1+, \mathrm{y}}\right)\right]
$$

where $\bar{w}_{0, y}$ and $\bar{w}_{1+, y}$ are the mean weight of group 0 and group $1+$ individuals for the fishing season $y . \% w_{1+, y}$ was then applied to CGFS catch data to calculate the catch in weight of group 1+ individuals. From 2005 to 2014, group 1+ individuals represented on average $91.5 \%$ of the CGFS catch-in-weight, with a very small between-year CV of 0.056 . As length data for CGFS survey were available from 2005 only, we used this mean value to calculate the pre-2005 catch-in-weight of $1+$ individuals. The catch of $1+$ individuals was then divided by trawl swept area for each haul. The resulting CPUE were averaged per strata $s$ with surfaces $A_{\mathrm{s}}$ (ICES rectangles). CPUE by stratum $U_{y, s}^{c g f s}$ were then raised to the VIId area (Fig. 1), and scaled so that the first value of the time series equals 1:

$$
U_{y}^{c g f s}=\frac{\sum_{s} A_{S} * U_{y, s}^{c g f s} / \sum_{s} A_{S}}{\sum_{s} A_{S} * U_{1, s}^{c g f s} / \sum_{s} A_{S}}
$$

The French LPUE were calculated using commercial data that provide information about the percentage in weight of one year-old cuttlefish by year and month. Following Gras et al. (2014), cuttlefish of commercial categories 1 and 2 (animals above $300 \mathrm{~g}$ ) were assumed to 
be $1+$ year old. We applied these percentages to separate group 0 and group $1+$ in the catches. The zero-inflation in the data was analysed using a Delta-GLM (Fletcher et al., 2005; Gras et al., 2014; Lo et al., 1992; Stefansson, 1996) applied to each of the time series (aggregated by trip) with ICES statistical rectangle, vessel power, fishing season and month as factors. A year effect on the expected abundance indices was extracted and considered as a time series of abundance indices (Appendix B). The UK LPUE was not used in the model because no information was available to separate the 0 and 1+ age groups in the English catch.

In the two-stage biomass model, the time series of total catch by age group (from both French and UK vessels) were also needed. The same method as for the LPUE was used to estimate the percentage of the two age groups in the French catches for each year and quarter. For UK catches, the mean percentage of group 1+ individuals from 1992 to 2012 was applied from 2013 to 2015 to complete the time series.

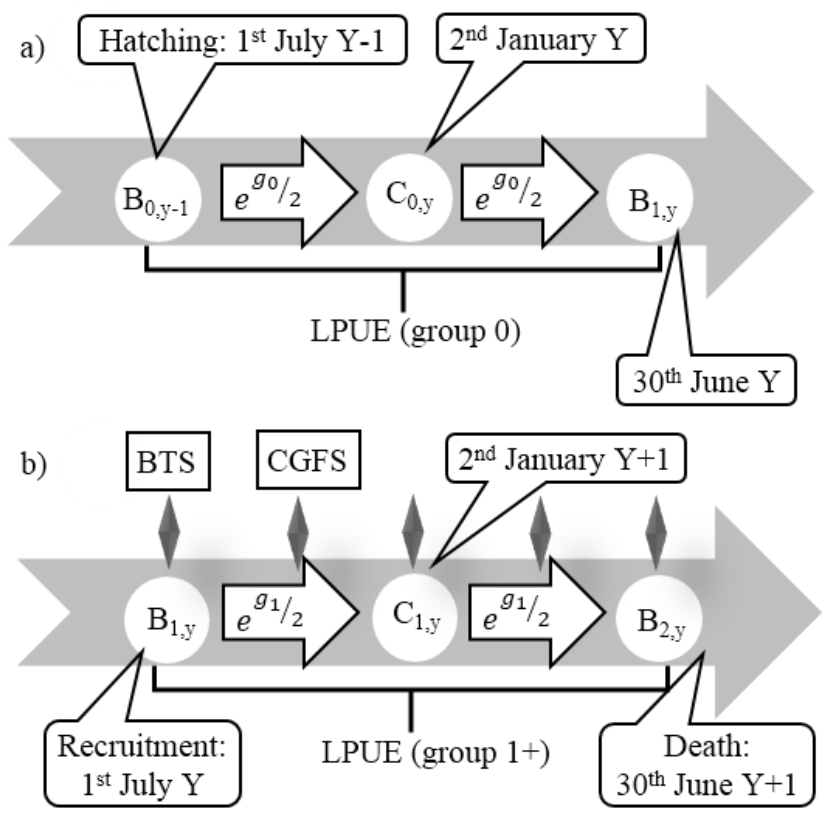

Fig. 2. The simplified life cycle of the English Channel stock of cuttlefish. For models M1, M2 and M4, only group 1+ individuals are modeled (b). For model M3, a cohort of group 0 individuals is added (a). The total catch of French and English fishery occurs as a pulse in the middle of the fishing season: $\mathrm{C}_{0, \mathrm{y}}$ for group 0 individuals, and $\mathrm{C}_{1, \mathrm{y}}$ for group $1+$ individuals.

\subsection{The two-stage biomass model}

The model is based on a simplified cuttlefish life cycle (Fig. 2): we consider an exclusive 2 years lifespan, with massive natural mortality occurring shortly after spawning on June $30^{\text {th }}$. Each fishing season extends from July $1^{\text {st }}$ (when one year-old individuals are recruited to the fishery) to June $30^{\text {th }}$ of the following year (one year later, remaining individuals are mature and have spawned). We use subscript $y$ to refer to the fishing season. Catch of cuttlefish of the two age groups $0+$ and $1+$ (denoted $C_{0, y}$ and $C_{1, y}$ for $0+$ and $1+$ group, respectively) is assumed to happen as a coordinated pulse in the middle of the fishing season (on January $2^{\text {nd }}$ ).

We first define the baseline model M1 for the English Channel cuttlefish stock, and then the variants M2, M3 and M4. The model M1 captures the dynamics of group 1+ individuals only. It assumes an intrinsic biomass growth rate parameter $g_{1, y}$ specific to group $1+$, based on mortality and growth coefficients specific to this class. A hierarchical structure is assumed for the $g_{1, y}$ 's to capture variation among years. The model is fitted to time series of 
total catches, and BTS, CGFS and French LPUE abundance indices, where CGFS, French LPUE and total catch are processed to account for 1+ age group only. Models M2, M3 and M4 are constructed to assess the sensitivity of results to alternative model structures and sources of data (Table 2).

\subsubsection{Baseline model M1 with one single cohort (1+ age group)}

\subsubsection{Biomass dynamics}

Let $B_{1, \mathrm{y}}$ be the biomass of the 1+ group at the start of the fishing season. A hierarchical lognormal structure is set on the $B_{1, \mathrm{y}}$ 's to capture variation among years:

$$
\log \left(B_{1, \mathrm{y}}\right) \sim \mathrm{N}\left(\log \left(\mu_{B_{1}}\right)-\frac{1}{2}{\sigma_{B 1}}^{2},{\sigma_{B 1}}^{2}\right)
$$

with a grand mean $\mu_{B_{1}}$ a priori drawn from an informative lognormal prior distribution and a variance $\sigma_{B 1}{ }^{2}$ a priori drawn from an uninformative prior distribution (Table 1). The unexploited biomass estimated on $1^{\text {st }}$ October $\left(B_{1 . o c t, y}\right)$ without catch removals is defined as follows:

$$
\log \left(B_{1 . o c t, y}\right) \sim \mathrm{N}\left(\log \left(B_{1, y} e^{\frac{g_{1, y}}{4}}\right)-\frac{1}{2} \sigma_{\text {process }}^{2}, \sigma_{\text {process }}^{2}\right)
$$

where $g_{1, \mathrm{y}}$ is the biomass growth rate parameter of group $1+$ individuals, and lognormal process errors $\sigma_{\text {process }}^{2}=\log \left(C V_{\text {process }}^{2}+1\right)$, with $C V_{\text {process }}$ drawn from an informative prior distribution (see Table 1).

The unexploited biomass estimated on $1^{\text {st }}$ January $\left(B_{1 . j a n, \mathrm{y}}\right)$ without catch removals is defined as follows:

$$
\log \left(B_{1 . j a n, y}\right) \sim \mathrm{N}\left(\log \left(B_{1 . o c t, y} e^{\frac{g_{1, y}}{4}}\right)-\frac{1}{2} \sigma_{\text {process }}^{2}, \sigma_{\text {process }}^{2}\right)
$$

The spawning stock biomass $B_{2, y}$ of fishing season $y$ is expressed as:

$$
\log \left(B_{2, y}\right) \sim \mathrm{N}\left(\log \left(\left[B_{1 . j a n, y}\left(1-E_{1, y}\right)\right] e^{\frac{g_{1, y}}{2}}\right)-\sigma_{\text {process }}^{2}, 2 * \sigma_{\text {process }}^{2}\right)
$$

where $E_{1, \mathrm{y}}$ is the exploitation rate for group $1+$ individuals and the process error variance is twice the $\sigma_{\text {process }}^{2}$ to account for the fact that the time step is twice that given in Eqns 4 and 5 .

\subsubsection{Observation equations}

The expected values of the catches are calculated as the biomass in the middle of the fishing season $\left(B_{1 . j a n, y}\right)$ multiplied by the exploitation rate $E_{1, \mathrm{y}}$. Catches of $1+$ animals are then assumed to be observed with lognormal observation errors with a coefficient of variation $C V_{C 1}$. An informative prior distribution that favors small values of $\mathrm{CV}$ is specified in order to imitate the prior expectation that catches are assumed to be well known for trawlers (see Table 1).

$$
\log \left(C_{1, y}\right) \sim N\left(\log \left(E_{1, y} B_{1 . j a n, y}\right)-\frac{1}{2} \sigma_{C 1}^{2}, \sigma_{C 1}^{2}\right)
$$

As the BTS survey occurs in July, the BTS abundance indices provide information on the biomass of one-year old cuttlefish at the start of the fishing season $\left(B_{1, y}\right)$. The CGFS survey occurs three months later, so abundance indices are assumed to be noisy observation of the biomass of group 1+ individuals one quarter after the beginning of the fishing season 
$\left(B_{1 . o c t, y}\right)$. The BTS and CGFS survey indices (denoted $U_{y}^{b t s}$ and $U_{y}^{c g f s}$, respectively) are assumed to be an indirect observation of the biomasses $B_{1, y}$ and $B_{1 . o c t, y}$ with catchabilities $q_{\mathrm{bts}}$ and $q_{\mathrm{cgfs}}$ and lognormal observation errors with variances $\sigma_{b t s}^{2}$ and $\sigma^{2}{ }_{c g f s}$, drawn from a non-informative prior distribution (Table 1):

$$
\left\{\begin{array}{c}
\log \left(U_{y}^{b t s}\right) \sim N\left(\log \left(q_{b t s} B_{1, y}\right)-\frac{1}{2} \sigma_{b t s}^{2}, \sigma_{b t s}^{2}\right) \\
\log \left(U_{y}^{c g f s}\right) \sim \mathrm{N}\left(\log \left(q_{\mathrm{cgfs}} B_{1 . o c t, y}\right)-\frac{1}{2} \sigma_{c g f s}^{2}, \sigma^{2}{ }_{c g f s}\right)
\end{array}\right.
$$

Two different observation error variances are used in Eqn 8 because the CGFS data are supposed to be less reliable before 2005, with CV before 2005 being twice that after 2005 . Finally, the French standardized LPUE for group $1+$ animals $\left(U_{y}^{\text {lpue1 }}\right)$ is assumed to be a lognormal observation of the mean of the biomass between the start and the end of the fishing season (with catchability $q_{\text {lpuel }}$ ) with variance $\sigma_{l p u e 1}^{2}$ :

$$
\log \left(U_{y}^{l p u e 1}\right) \sim \mathrm{N}\left(\log \left(\frac{1}{2} q_{\text {lpue } 1}\left[B_{1, y}+B_{2, y}\right]\right)-\frac{1}{2} \sigma_{l p u e 1}^{2}, \sigma_{l p u e 1}^{2}\right)
$$

\subsubsection{Priors}

We developed a prior for the intrinsic biomass growth rate parameter $g_{1, \mathrm{y}}$ for the group $1+$ individuals defined as the difference between the mean growth coefficient $(G r)$ and the natural mortality rate $(M)$ (Appendix A). A lognormal hierarchical structure with grand mean $\mu_{g 1}$ (drawn from an informative lognormal prior distribution; Table 1) and variance $\sigma_{g 1}{ }^{2}$ (drawn from a non-informative prior distribution; Table 1) is defined on the $g_{1, \mathrm{y}}$ 's:

$$
\log \left(g_{1, \mathrm{y}}\right) \sim \mathrm{N}\left(\log \left(\mu_{g_{1}}\right)-\frac{1}{2}{\sigma_{g 1}}^{2},{\sigma_{g 1}}^{2}\right)
$$

The exploitation rate is drawn a priori from a weakly informative beta prior distribution, allowing $E_{1, y}$ to take any value between 0 and 1 . The variances of the observation errors for the abundance indices, $\sigma_{b t s}^{2}, \sigma_{c g f s}^{2}$ and $\sigma_{l p u e 1}^{2}$ are all drawn from uninformative inversegamma distributions.

A sensitivity of the baseline model M1 to the prior distribution of $g_{1, y}$ and on $B_{1}$ was evaluated. A percentage of $+/-20 \%$ was applied to the mean values used for the construction of both priors. The sensitivity to the variation coefficient controlling the a priori inter-year variation in catch was also evaluated (Table 3 ).

\subsubsection{Alternative model structure and sensitivity analysis}

Model M2 is an alternative to the baseline model M1 that assumes that $g$ is constant over the years, with a value of 0.89 . Comparing the results between M1 and M2 allows us to quantify the benefits of considering inter-year variability in $g$ (Table 2; Eqn 11).

Model M3 explores the feasibility of modeling both the $0+$ and the $1+$ cohorts using an additional LPUE index calculated for 0+ age group. The results from Model 3 are compared to those from model M1 to evaluate the influence of considering the dynamics of group 0 and 1+ individuals (instead of 1+ only for M1). The cohort dynamics start with a lognormal hierarchical prior on the biomass of group 0 animals (denoted $B_{0, y}$ ) with grand mean $\mu_{B_{0}}$ and variance $\sigma_{B 0}{ }^{2}$ drawn from an informative and non-informative prior distribution respectively (see Table 1):

$$
\log \left(\mathrm{B}_{0, \mathrm{y}}\right) \sim \mathrm{N}\left(\log \left(\mu_{\mathrm{B}_{0}}\right)-\frac{1}{2}{\sigma_{\mathrm{B} 0}}^{2},{\sigma_{\mathrm{B} 0}}^{2}\right)
$$


The biomass of the $0+$ group then grows with growth rate $g_{0, y}$ to provide the biomass of $0+$ group in October then in January when they can be exploited with harvest rate $E_{0, y}$ before being recruited as $1+$ group in July at the start of the fishing season $y+1$ :

$$
\begin{gathered}
\log \left(\mathrm{B}_{0 . \mathrm{oct}, \mathrm{y}}\right) \sim \mathrm{N}\left(\log \left(\mathrm{B}_{0, \mathrm{y}} \mathrm{e}^{\frac{\mathrm{g}_{0, \mathrm{y}}}{4}}\right)-\frac{1}{2} \sigma_{\text {process }}^{2}, \sigma_{\text {process }}^{2}\right) \\
\log \left(B_{0 . \mathrm{jan}, y}\right) \sim \mathrm{N}\left(\log \left(B_{0 . \mathrm{oct}, y} e^{\frac{g_{0, y}}{4}}\right)-\frac{1}{2} \sigma_{\text {process }}^{2}, \sigma_{\text {process }}^{2}\right) \\
\log \left(B_{1, y+1}\right) \sim \mathrm{N}\left(\log \left(\left[B_{0 . j a n, y}\left(1-E_{0, y}\right)\right] e^{\frac{g_{0, y}}{2}}\right)-\sigma_{\text {process }}^{2}, 2 * \sigma_{\text {process }}^{2}\right)
\end{gathered}
$$

A lognormal hierarchical prior with a grand mean $\mu_{g_{0}}$ and variance $\sigma_{g 0}{ }^{2}$ (Table 1 ) is set for $g_{0, \mathrm{y}}$ :

$$
\log \left(g_{0, \mathrm{y}}\right) \sim \mathrm{N}\left(\log \left(\mu_{g_{0}}\right)-\frac{1}{2} \sigma_{g 0}{ }^{2}, \sigma_{g 0}{ }^{2}\right)
$$

Additional observation equations (Eqns 17 and 18) are needed to incorporate information from the French LPUE and the catches of group 0 cuttlefish:

$$
\begin{aligned}
& \log \left(U_{y}^{\text {lpue } 0}\right) \sim \mathrm{N}\left(\log \left(\frac{1}{2} q_{\text {lpue } 0}\left[B_{0, y}+B_{0, y} e^{g_{0, y}}\left(1-E_{0, y}\right)\right]\right)-\frac{1}{2} \sigma_{\text {lpue } 0}^{2}, \sigma_{\text {lpue } 0}^{2}\right) \\
& \log \left(C_{0, y}\right) \sim N\left(\log \left(E_{0, y} B_{0, y} e^{\frac{g_{0, y}}{2}}\right)-\frac{1}{2} \sigma_{C 0}^{2}, \sigma_{C 0}^{2}\right)
\end{aligned}
$$

where $q_{\text {lpue } 0}$ is the catchability of French trawlers for group 0 individuals, and $\sigma_{\text {lpue }}^{2}$ is the unknown variance of the lognormal observation errors, drawn from an uninformative prior distribution (Table 1). Catches of $0+$ animals are assumed to be observed with lognormal observation errors with variance $\sigma_{C 0}^{2}$ derived from the informative prior distribution on the coefficient of variation $C V_{C 0}$ (Table 1). The sensitivity of the results of model M3 to the prior distribution of $g_{0, y}$ and of $B_{0}$ was evaluated. A percentage of $+/-20 \%$ was applied to the mean values used for the construction of both priors. Sensitivity to the variation coefficient controlling the a priori inter-year variation in catch was also evaluated (Table 3 ).

Model M4 is similar to Model M1, but does not include the French LPUE abundance

\begin{tabular}{|c|c|c|c|}
\hline & Parameter & Alternative priors tested & Name of the model run \\
\hline \multirow{5}{*}{$\bar{\Sigma}$} & $\mu_{\mathrm{B} 1}$ & $\operatorname{Lognormal}(\mu=12000, \mathrm{CV}=0.1)$ & Smaller $\mu_{\mathrm{B} 1}$ \\
\hline & $\mu_{\mathrm{B} 1}$ & $\operatorname{Lognormal}(\mu=18000, \mathrm{CV}=0.1)$ & Higher $\mu_{\mathrm{B} 1}$ \\
\hline & $\mu_{\mathrm{g} 1}$ & $\operatorname{Lognormal}(\mu=0.71, \mathrm{CV}=0.1)$ & Smaller $\mu_{\mathrm{g} 1}$ \\
\hline & $\mu_{\mathrm{g} 1}$ & $\operatorname{Lognormal}(\mu=1.07, \mathrm{CV}=1.07)$ & Higher $\mu_{\mathrm{g} 1}$ \\
\hline & $\mathrm{CV}_{\mathrm{C} 1}$ & $\mathrm{CV}_{\mathrm{C} 1} \sim \operatorname{Exp}(4)$ & Higher $\mathrm{CV}_{\mathrm{C} 1}$ \\
\hline \multirow{5}{*}{$\sum^{m}$} & $\mu_{\mathrm{B} 0}$ & $\operatorname{Lognormal}(\mu=4000, \mathrm{CV}=0.5)$ & Smaller $\mu_{\mathrm{B} 0}$ \\
\hline & $\mu_{\mathrm{B} 0}$ & $\operatorname{Lognormal}(\mu=6000, \mathrm{CV}=0.5)$ & Higher $\mu_{\mathrm{B} 0}$ \\
\hline & $\mu_{\mathrm{g} 0}$ & $\operatorname{Lognormal}(\mu=0.78, \mathrm{CV}=0.1)$ & Smaller $\mu_{\mathrm{g} 0}$ \\
\hline & $\mu_{\mathrm{g} 0}$ & $\operatorname{Lognormal}(\mu=1.16, \mathrm{CV}=0.1)$ & Higher $\mu_{\mathrm{g} 0}$ \\
\hline & $\mathrm{CV}_{\mathrm{C} 0}$ & $\mathrm{CV}_{\mathrm{C} 0} \sim \operatorname{Exp}(4)$ & Higher $\mathrm{CV}_{\mathrm{C} 0}$ \\
\hline
\end{tabular}
indices, and therefore enabled us to assess the sensitivity of the results to the data and to explore the capacity of the model to forecast the biomass of age-1 group at the start of the year, $B_{1 . j a n}$.

Table 3

Alternative priors explored in sensitivity analyses. 


\subsection{Model comparison}

The deviance information criterion (DIC) and the normalized root mean-squared error (NRMSE) were used to compare the models. The DIC is a Bayesian measure of fit, which includes a penalty term for model complexity, and was used to compare models fitted to the same data sets (M1 versus M2 and sensitivity analysis on M1 and M3). A difference of 7 between the models was assumed to provide strong evidence in favor of the model with the smaller DIC (Spiegelhalter et al., 2002). The capacity to fit the abundance indices time series was evaluated using NRMSE, which compares the difference between the observed abundance indices with posterior replicates of abundance indices. For each time series of length $L$, a NRMSE is calculated as follows:

$$
N R M S E=\frac{1}{S} \sum_{j=1}^{j=S} \sqrt{\frac{1}{L} \sum_{i=1}^{i=L}\left(\frac{y_{i}-\tilde{y}_{i}^{(j)}}{\bar{y}}\right)^{2}}
$$

where $y_{i}$ is the observed value of the abundance index $i$ (in log scale), $\tilde{y}_{i}^{(j)}$ is a replicated value drawn from the posterior predictive distribution (log scale), $\bar{y}$ is the mean of the time series of observed abundance indices (log scale) and $S$ is the size of the MCMC sample. The average over a large MCMC sample size enabled us to integrate over the posterior distribution of replicated abundance indices. Lower NRMSE values indicate a better fit to the time series.

We also calculated the posterior predictive $p$-values (Gelman et al., 2014) to evaluate how the model a posteriori fitted to the data (see an example in Archambault et al. (2016) for details on calculation). $p$-values concentrating near 0 or 1 indicate that the observed pattern would be unlikely to be seen in replications of the data if the model were true, and thus indicate lack of model fit.

\subsection{Computational details}

Three chains of 200,000 Markov Chain Monte Carlo (MCMC) samples were simulated using OpenBUGS (OpenBUGS V3.2.3 ; Lunn et al. 2009). A burn-in period of 10,000 samples was used to avoid dependence of the MCMC samples on the initial conditions, and each chain was thinned by 30 to reduce autocorrelation. Convergence of the MCMC simulations to the posterior distribution was checked using the Brooks-Gelman-Rubin (BGR) convergence diagnostic (Brooks and Gelman, 1998).

\section{Results}

\subsection{Results from the baseline model M1}

Results are plotted with years at the start of the fishing seasons on the $\mathrm{x}$-axis. Therefore, for a year $t$, estimates of $B_{1}$ are for July $t$, estimates of $B_{1 \text {.jan }}$ are for January $t+1$, and estimates of $B_{2}$ are in June $t+1$ even if the same fishing season $y$ is considered.

All observed abundance indices were within the range of 95\% Bayesian credible intervals of posterior replicates for French LPUE (Fig. 3b), BTS survey (Fig. 3c) and CGFS survey (Fig. 3d). The posterior predictive $p$-values (Table 4) ranged from 0.51 to 0.7, showing that there were no strong discrepancies between the model fitted a posteriori and the data. The model tended to slightly overestimate the CGFS abundance indices ( $p$-values $>0.5$ ). Posterior predictive $p$-values for BTS, LPUE and Catch were close to 0.5, indicating that the model is well able to reproduce these data. The fitted and observed catches were 
very similar (Fig. 3a), with high inter-year variability with no clear trend until 2006, and then a decreasing trend from 2006 to 2014.

Estimates (median of posterior distributions) of $B_{1}$ showed a decreasing trend from 2002 to 2014 (Fig. 4a). Estimates of B2 showed no clear trend (Fig. 4b). Estimates of $g_{1, y}$ from model M1 fluctuated between 0.64 and 0.83 from 1992 to 2008 with no particular trend and increased from 0.72 in 2008 to 1 in 2011. The highest value was estimated at 1.16 in 2014 (Fig. 4c). The exploitation rate varied between 0.4 and 0.64 from 1992 to 2008, and a drop to 0.25 occurred in 2009 (Fig. 4d). The highest values were obtained for the fishing seasons 2001 and 2011 (respectively 0.64 and 0.62 ) and were associated with low estimates of recruited biomass $B_{1}$ and spawning stock biomass $B_{2}$ in 2001, and high estimate of $g_{1, \mathrm{y}}$ in 2011.
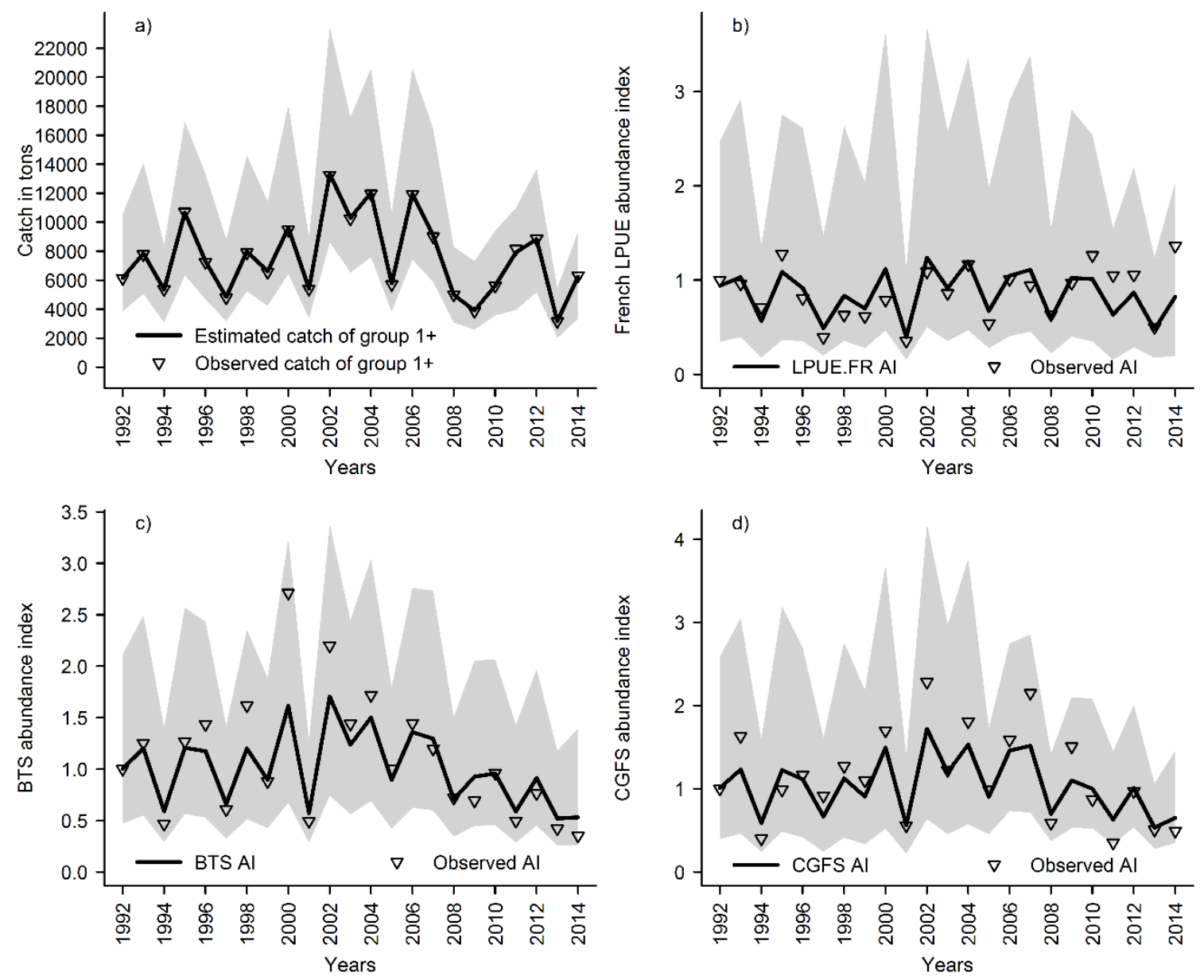

Fig. 3. A comparison of model M1 posterior median estimates with observed values for catch (a) and LPUE (b), BTS (c) and CGFGS (d) abundance indices. Solid lines: posterior medians. Shaded areas: 95\% Bayesian credible intervals. 
Table 4

Comparison of deviance information criterion (DIC) value, normalized root mean-squared error (NRMSE) and Bayesian p-values for all model runs.

\begin{tabular}{|c|c|c|c|c|c|c|c|c|c|c|c|c|c|}
\hline \multirow[t]{2}{*}{ Model run } & \multirow[t]{2}{*}{ DIC } & \multicolumn{6}{|c|}{ NRMSE } & \multicolumn{6}{|c|}{$p$-value } \\
\hline & & BTS & CGFS & \multicolumn{2}{|c|}{ LPUE } & \multicolumn{2}{|c|}{ Catch } & BTS & CGFS & \multicolumn{2}{|c|}{ LPUE } & \multicolumn{2}{|c|}{ Catch } \\
\hline Model M1 & 422 & 0.73 & 0.78 & \multicolumn{2}{|c|}{0.72} & \multicolumn{2}{|c|}{0.55} & 0.55 & 0.7 & \multicolumn{2}{|c|}{0.54} & \multicolumn{2}{|c|}{0.51} \\
\hline Smaller $\mu_{\mathrm{B} 1}$ & 422 & 0.74 & 0.78 & \multicolumn{2}{|c|}{0.7} & \multicolumn{2}{|c|}{0.54} & 0.54 & 0.7 & \multicolumn{2}{|c|}{0.54} & \multicolumn{2}{|c|}{0.51} \\
\hline Higher $\mu_{\mathrm{B} 1}$ & 422 & 0.74 & 0.77 & \multicolumn{2}{|c|}{0.74} & \multicolumn{2}{|c|}{0.57} & 0.57 & 0.7 & \multicolumn{2}{|c|}{0.54} & \multicolumn{2}{|c|}{0.51} \\
\hline Smaller $\mu_{\mathrm{g} 1}$ & 425 & 0.74 & 0.77 & \multicolumn{2}{|c|}{0.72} & \multicolumn{2}{|c|}{0.55} & 0.54 & 0.7 & \multicolumn{2}{|c|}{0.54} & \multicolumn{2}{|c|}{0.51} \\
\hline Higher $\mu_{\mathrm{g} 1}$ & 420 & 0.73 & 0.77 & \multicolumn{2}{|c|}{0.73} & \multicolumn{2}{|c|}{0.56} & 0.56 & 0.7 & \multicolumn{2}{|c|}{0.55} & \multicolumn{2}{|c|}{0.51} \\
\hline \multirow[t]{2}{*}{ Higher $\mathrm{CV}_{\mathrm{C} 1}$} & 442 & 0.74 & 0.77 & \multicolumn{2}{|c|}{0.72} & \multicolumn{2}{|c|}{0.59} & 0.55 & 0.71 & \multicolumn{2}{|c|}{0.54} & \multicolumn{2}{|c|}{0.54} \\
\hline & & BTS & CGFS & 0 & $1+$ & 0 & $1+$ & BTS & CGFS & 0 & $1+$ & 0 & $1+$ \\
\hline Model M3 & 818 & 0.76 & 0.81 & 0.81 & 0.71 & 0.46 & 0.54 & 0.54 & 0.7 & 0.53 & 0.55 & 0.51 & 0.51 \\
\hline Smaller $\mu_{\mathrm{B} 0}$ & 816 & 0.76 & 0.81 & 0.81 & 0.7 & 0.46 & 0.53 & 0.53 & 0.7 & 0.52 & 0.55 & 0.51 & 0.51 \\
\hline Higher $\mu_{\mathrm{B} 0}$ & 815 & 0.76 & 0.81 & 0.81 & 0.7 & 0.47 & 0.53 & 0.54 & 0.71 & 0.51 & 0.54 & 0.51 & 0.51 \\
\hline Smaller $\mu_{\mathrm{g} 0}$ & 816 & 0.77 & 0.81 & 0.8 & 0.7 & 0.46 & 0.53 & 0.54 & 0.71 & 0.52 & 0.55 & 0.51 & 0.51 \\
\hline Higher $\mu_{\mathrm{g} 0}$ & 818 & 0.76 & 0.81 & 0.8 & 0.7 & 0.46 & 0.54 & 0.54 & 0.7 & 0.52 & 0.54 & 0.52 & 0.51 \\
\hline Higher $\mathrm{CV}_{\mathrm{C} 0}$ & 837 & 0.76 & 0.81 & 0.8 & 0.7 & 0.51 & 0.54 & 0.54 & 0.71 & 0.5 & 0.54 & 0.53 & 0.51 \\
\hline
\end{tabular}

\subsection{Sensitivity of M1 estimates to the priors}

Overall, the results of model M1 were only slightly sensitive to modifications to the

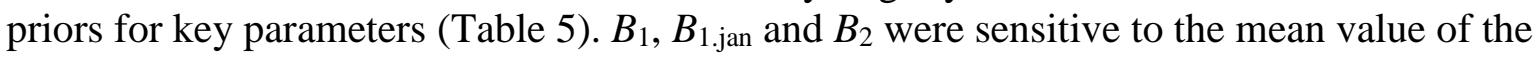
prior distribution of $B_{1}$, varying by up to $14 \%$. Changes to the mean value of the prior on $g_{1, \mathrm{y}}$ impacted mainly the estimates of $g_{1, y}$ and $B_{2}$, with respectively up to $17 \%$ and $11 \%$ variation. Exploitation rate estimates were mostly sensitive to the choice of prior distribution of the grand mean with variation up to $8 \%$. The sensitivity of the catches were less than $1 \%$ for all model runs and are consequently not shown.

The only significant difference of DIC value was observed for the model run with higher $\mathrm{CV}$ on catches (Table 4) and indicates a better fit of the base model M1 compared to the model with higher CV on catches. The NRMSE showed no noticeable differences of fit for the three abundance index time series during the various trials.

Table 5

Mean percentage of variation between posterior means from model M1 and posterior means from the other model runs. The mean of percentages from all fishing seasons is given for each parameter and each model run. The CV related to the variation between fishing seasons is specified in brackets.

\begin{tabular}{|c|c|c|c|c|c|c|}
\hline & & Smaller $\mu_{\mathrm{B} 1}$ & Higher $\mu_{\mathrm{B} 1}$ & Smaller $\mu_{\mathrm{g} 1}$ & Higher $\mu_{\mathrm{g} 1}$ & Higher $\mathrm{CV}_{\mathrm{C} 1}$ \\
\hline \multirow{6}{*}{$\bar{\Sigma}$} & $B_{1}$ & $-10.7(0.4)$ & $8.1(0.4)$ & $3.4(1)$ & $-3.5(0.8)$ & $0.67(0.8)$ \\
\hline & $B_{1 . \text { jan }}$ & $-8.3(0.3)$ & $5.9(0.3)$ & $-2.6(0.5)$ & $2.2(0.5)$ & $1.8(1)$ \\
\hline & $B_{2}$ & $-14.3(0.17)$ & $9.6(0.2)$ & $-10.4(0.6)$ & $10.9(0.7)$ & $1.1(1.8)$ \\
\hline & $g_{1}$ & $1.7(1)$ & $-0.8(1.1)$ & $-17.1(0.2)$ & $15.5(0.3)$ & $0.9(1.5)$ \\
\hline & $E_{1}$ & $8.1(0.3)$ & $-4.5(0.3)$ & $2.2(0.6)$ & $-1.7(0.7)$ & $0.8(1.3)$ \\
\hline & & Smaller $\mu_{\mathrm{B} 0}$ & Higher $\mu_{\mathrm{B} 0}$ & Smaller $\mu_{\mathrm{g} 0}$ & Higher $\mu_{\mathrm{g} 0}$ & Higher CV $\mathrm{C}_{\mathrm{C}}$ \\
\hline \multirow{7}{*}{$\stackrel{m}{\Sigma}$} & $B_{0}$ & $-0.38(1.5)$ & $0.9(0.54)$ & $14.3(0.08)$ & $-11.7(0.07)$ & $1.34(0.4)$ \\
\hline & $B_{1}$ & $-0.3(1.2)$ & $-0.04(13.3)$ & $-1.6(0.4)$ & $1.37(0.8)$ & $0.13(3.7)$ \\
\hline & $B_{2}$ & 0.19 (7.9) & $-0.4(3.6)$ & $-2.2(1)$ & $2.2(1)$ & $0.88(1.5)$ \\
\hline & $g_{0}$ & $0.12(4)$ & $-0.9(0.5)$ & $-19.4(0.03)$ & $18.1(0.03)$ & $-0.8(0.6)$ \\
\hline & $g_{1}$ & $0.67(1.1)$ & $-0.02(40)$ & $1.1(0.9)$ & $-0.69(1.4)$ & $0.03(24.6)$ \\
\hline & $E_{0}$ & $0.18(2.9)$ & $-0.5(0.7)$ & $-3.9(0.2)$ & $3.8(0.3)$ & $0.5(2.4)$ \\
\hline & $E_{1}$ & $0.09(7.5)$ & $0.17(2.6)$ & $1(0.8)$ & $-0.95(0.8)$ & $-0.32(1.3)$ \\
\hline
\end{tabular}




\subsection{Assuming a constant $g_{1}$ (models $M 1$ versus $M 2$ )}

Model M1, which assumed a time-varying $g_{1, \mathrm{y}}$ outperformed the model with a constant value of $g_{1}$ over the years (M2) because a lower DIC value was obtained for model M1 (Table 6) and a lower value of NRMSE was observed for LPUE for model M1, indicating a better fit to the data. $p$-values for BTS, LPUE and catch were not impacted by the change from model M1 to model M2.

Estimates of $g_{1, y}$ from model M1 were smaller than the grand mean (0.89), except for years 2011 and 2014 (Fig. 4c). $B_{1}$ estimates were very close for both models M1 and M2 (Fig. 4a), but model M2 provided slightly higher estimates of $B_{2}$ (Fig. 4b). Posterior estimates of exploitation rates followed the same trend, but estimates from model M1 were slightly higher (Fig. 4d).

The limited effect of setting a time-varying $g_{1, \mathrm{y}}$ on $B_{1}$ and $E$ estimates (Figs $4 \mathrm{a}$ and $4 \mathrm{~d}$ ) is in accordance with the sensitivity analysis conducted on the mean value used for the prior distribution of $g_{1, y}$ (Table 5). Changes to the mean value for $g_{1, y}$ prior distribution had little effect on the estimates of $B_{1}$ and $E$, but a higher effect on $B_{2}$. Differences between $B_{2}$ values estimated by models M1 and M2 ranged from 128 to 4,080 tons (Fig. 4b).
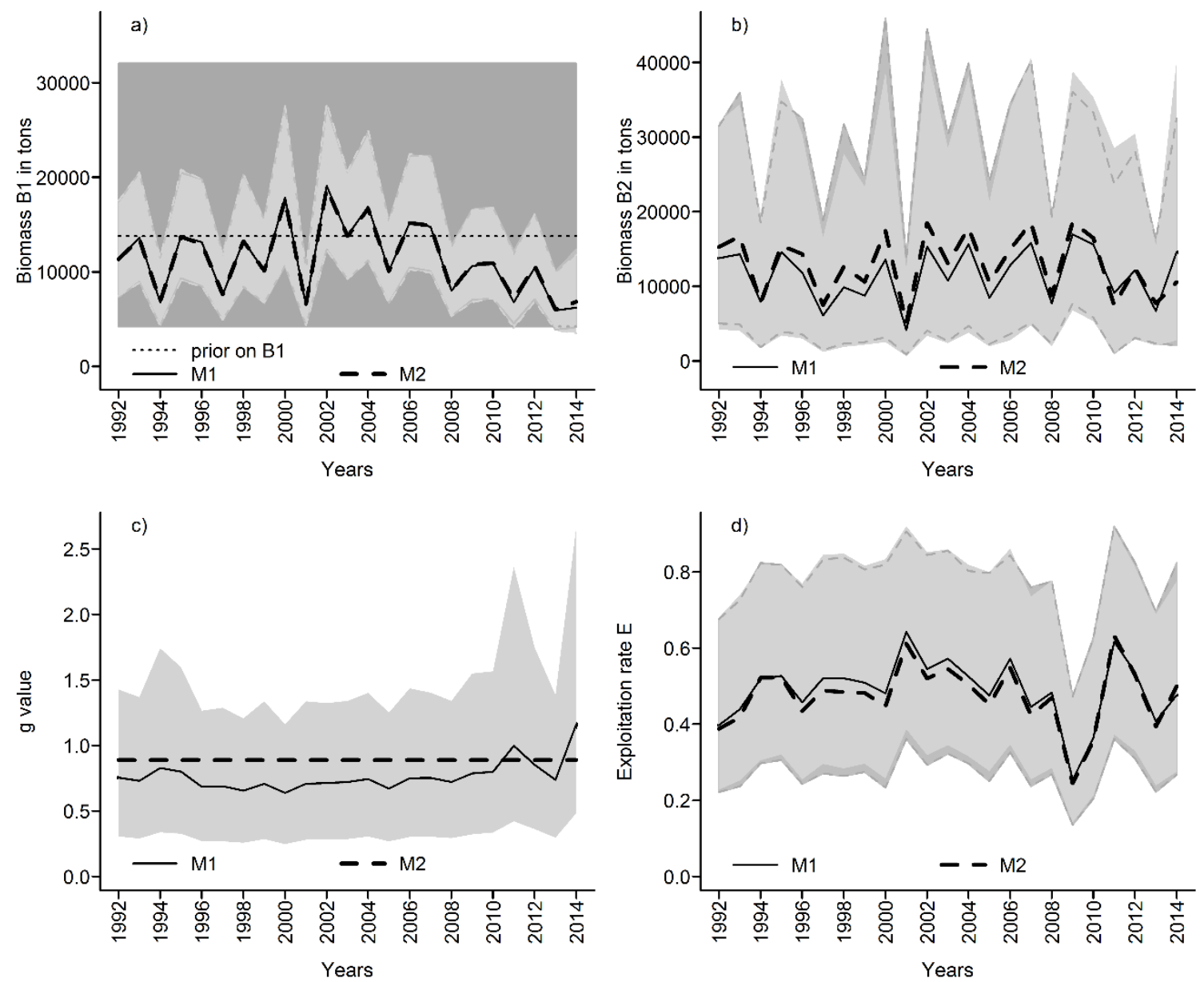

Fig. 4. A comparison of $\mathrm{B}_{1}$ (a), $\mathrm{B}_{2}$ (b), $g$ (c) and $E$ (d) for models $\mathrm{M} 1$ and $\mathrm{M} 2$. Solid lines: posterior medians for model M1. Dotted lines in bold: posterior medians for model M2. Dotted line (a): B1 prior medians. Shaded areas: 95\% Bayesian credible intervals (Lightgrey for model M1, grey for model M2, and darkgrey for the prior distribution of $\mathrm{B}_{1}$ ). 
Comparison of deviance information criterion (DIC), normalized root mean-squared error (NRMSE) and Bayesian $p$-values for all models.

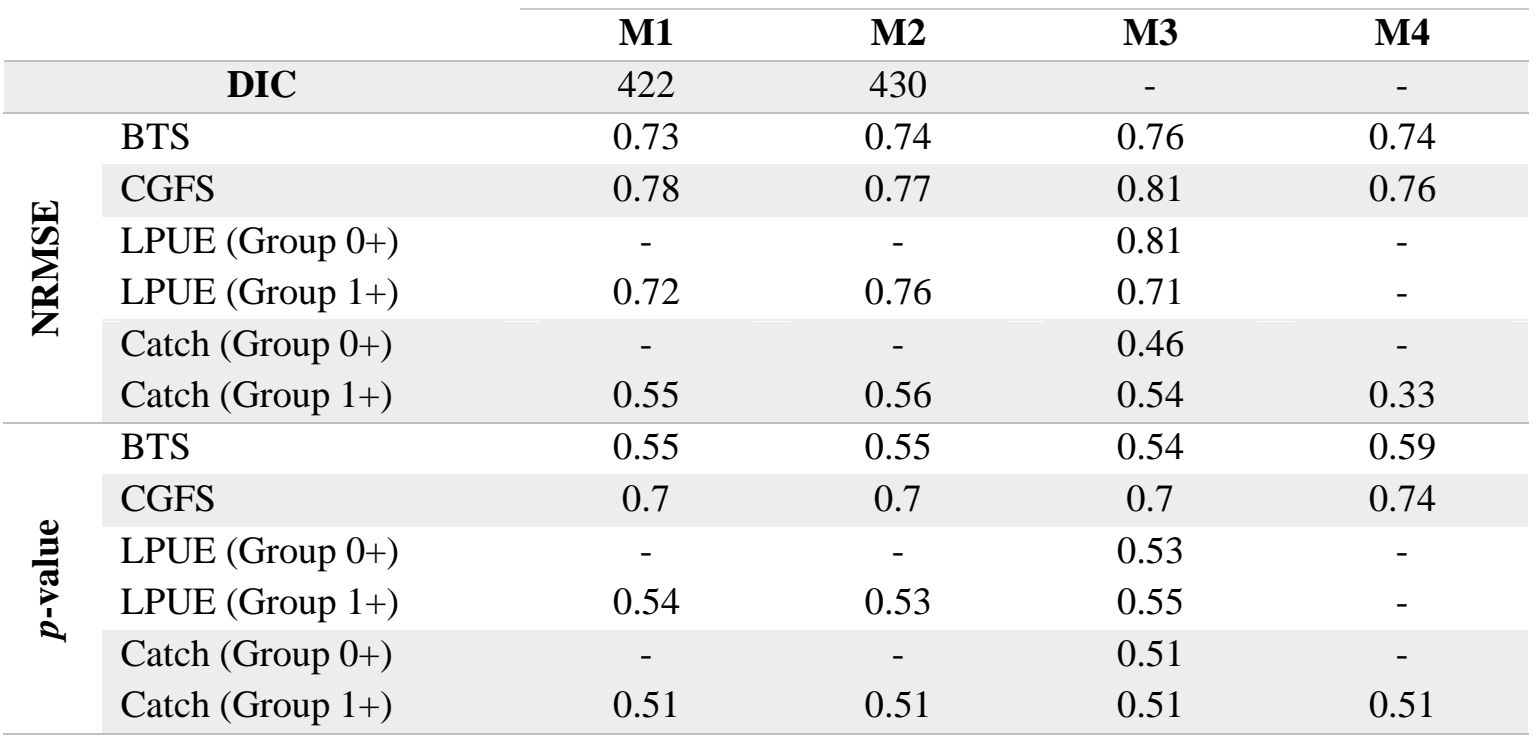

\subsection{Including the 0+ group in the dynamics (models M1 versus M3)}

Overall, extending the model to include the 0+ group did not improve the fit of $1+$ group category of the model (the one that is common to models M1 and M3). Differences in $p$ values between models M1 and M3 were weak for all abundance indices (Table 6). NRMSE values for BTS and CGFS were slightly lower for model M1 than for model M3 (Table 6; Figs 5c and 5d), indicating a better fit to the data. NRMSE values for model M3, for the LPUE of group 1+ individuals were smaller than for the LPUE of group 0 individuals, indicating a better fit to the LPUE of group 1+ individuals (Table 6; Fig. 5b).

Estimates of $B_{0}$ for model M3 showed little variation (Fig. 6a), but were sensitive to the prior distribution of $g_{0, \mathrm{y}}$ (Table 5). Estimates of $B_{1}$ and $B_{2}$ were smaller for model M3 than for model M1 (Figs 6a and 6b). Estimates of $g_{1, y}$ were similar for models M1 and M3. Estimates of $g_{0, y}$ were sensitive to the prior distribution of $g_{0, y}$ with up to $19 \%$ variation in posterior means (Table 5; Fig. 6c). The exploitation rate estimated for group 1+ individuals followed the same trend for models M1 and M3, but model M3 had higher estimates. The exploitation rate of group 0 individuals increased greatly between 1992 and 2000, as well as the catch of group 0 individuals (Figs 5a and 6d).

The sensitivity analysis conducted on model M3 showed that changes to the prior distribution of $B_{0, y}$ or to the prior distribution of $g_{0, y}$ had little effect on DIC, NRMSE and the $p$-values (Table 4). However, the model with a higher CV on catches was associated with higher DIC and NRMSE values for the catch of group 0 animals, indicating a better fit of the model M3 with baseline priors (Table 4). 

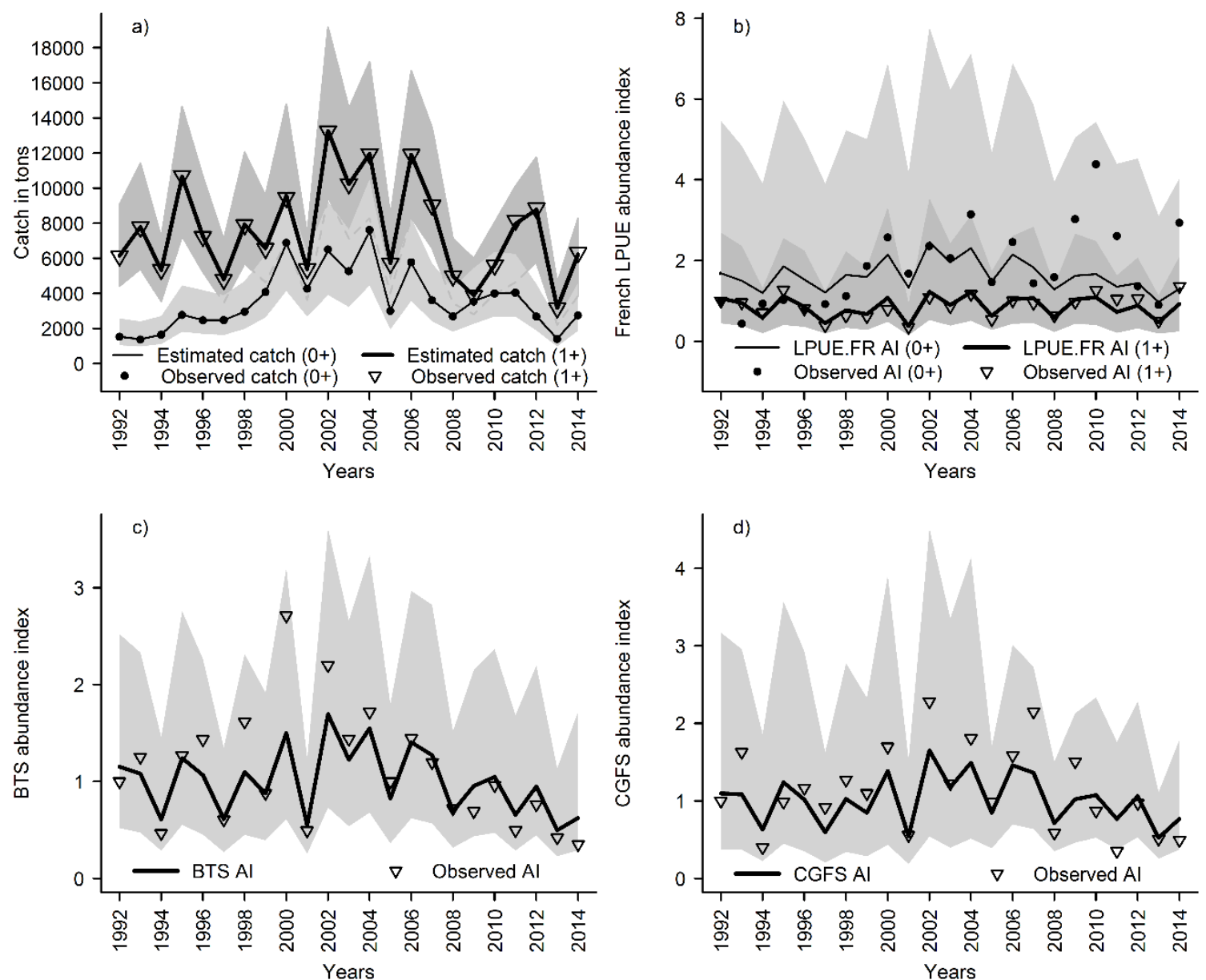

Fig. 5. A comparison of model M3 posterior median estimates with observed values for catch (a) and LPUE (b), BTS (c) and CGFGS (d) abundance indices. Solid lines: posterior medians. Shaded areas: 95\% Bayesian credible intervals. 

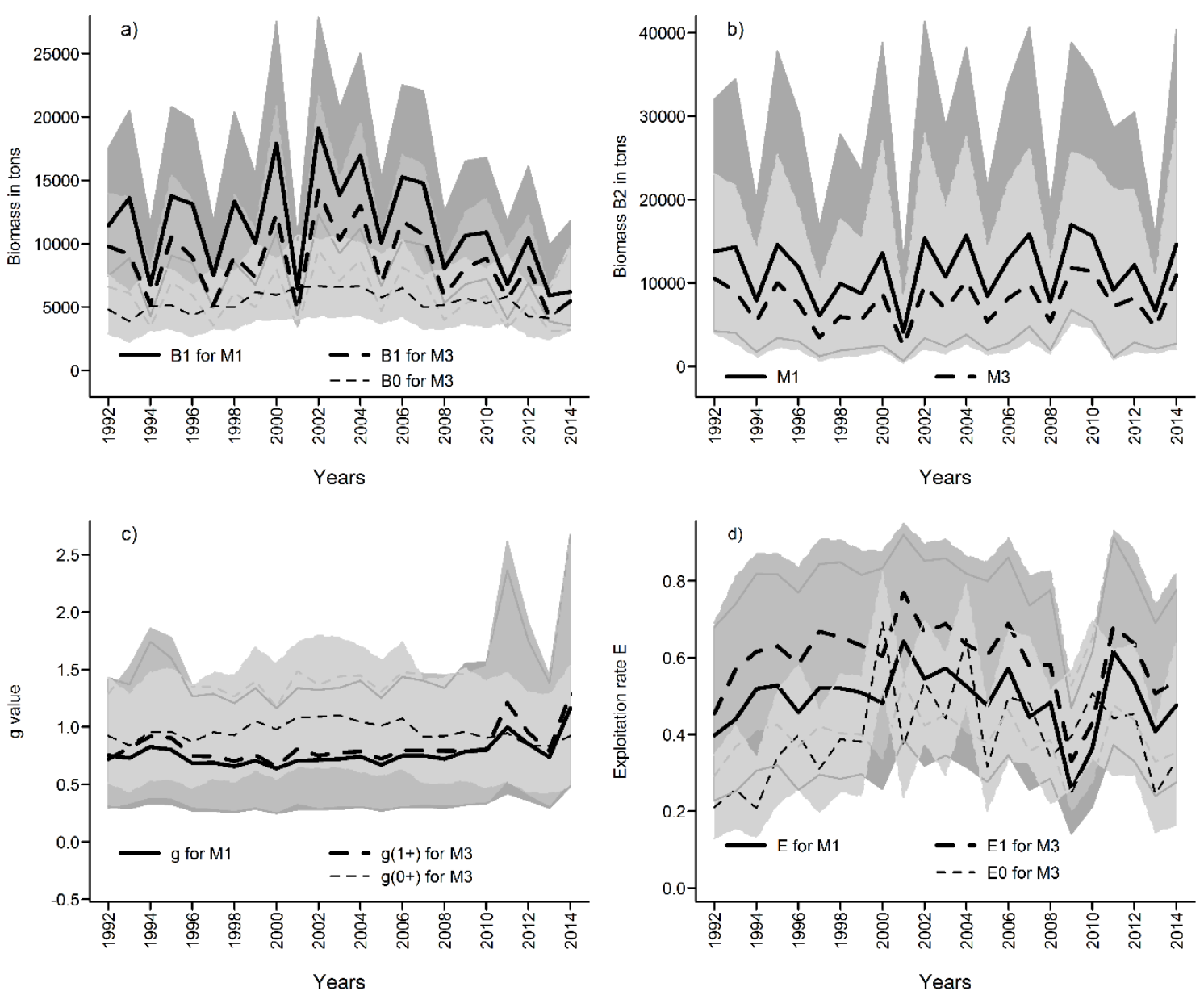

Fig. 6. A comparison of $\mathrm{B}_{1}(\mathrm{a}), \mathrm{B}_{2}$ (b), $g$ (c) and $E$ (d) for models $\mathrm{M} 1$ and $\mathrm{M} 3$. Solid lines: posterior medians for model M1. Dotted lines: posterior medians for model M3. Shaded areas: 95\% Bayesian credible intervals (Light grey for model M1 and grey for model M3).

\subsection{Effect of deleting the French LPUE abundance indices (models M1 versus M4)}

Overall, model M4 did not show any improved performance with regards to model M1. NRMSE values of catch were smaller for model M4 than for model M1, indicating a better fit. However, the $p$-values for the BTS and CGFS were higher for model M4 than for model M1, indicating a better fit of model M1 (Table 6). Model M4 provided less variable estimates of $g_{1, y}$ (Fig. 7c), but more variable estimates of the exploitation rate (Fig. $7 \mathrm{~d}$ ) than model M1. The lower variability of the estimates of $g_{1, y}$ in model M4 is in accordance with lack of information from the LPUE to update the prior distribution of $g_{1, \mathrm{y}}$. The estimates of $\mathrm{B}_{1}$ and $\mathrm{B}_{1 . j a n}$ (Figs 7a and 7b) followed the same trend as for models M1 and M4. Because the French LPUE abundance indices were higher than survey abundance indices for the last five fishing seasons (Figs 3b, 3c and 3d), results of model M4 showed a slightly greater decreasing trend between 2002 and 2014 than in model M1. 

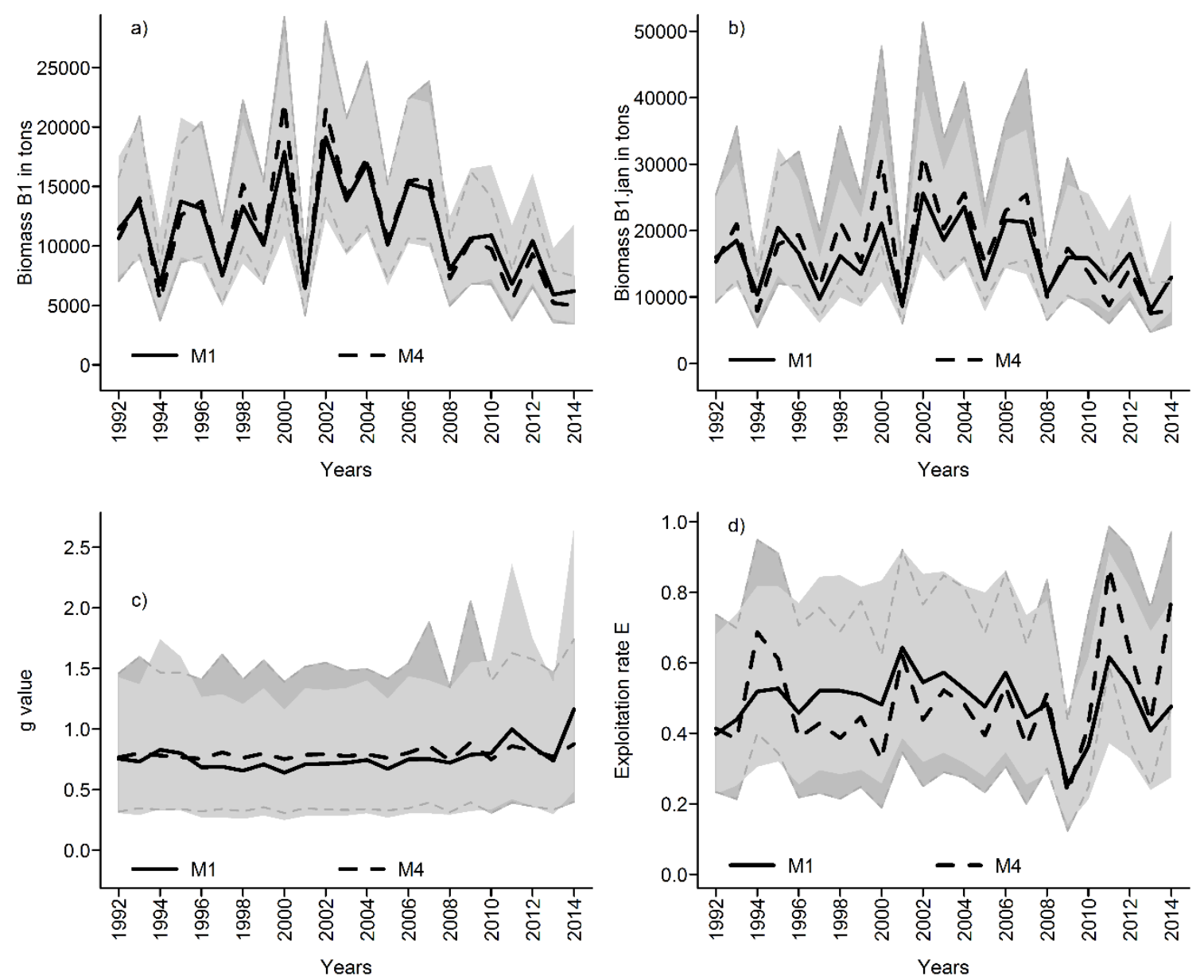

Fig. 7. A comparison of $\mathrm{B}_{1}(\mathrm{a}), \mathrm{B}_{1 . j a n}(\mathrm{~b}), g(\mathrm{c})$ and $E$ (d) for models $\mathrm{M} 1$ and $\mathrm{M} 4$. Solid lines: posterior medians for model M1. Dotted lines: posterior medians for model M4. Shaded areas: 95\% Bayesian credible intervals (Light grey for model M1 and grey for model M4).

\section{Discussion}

\subsection{A new two stage biomass dynamic model for cuttlefish in the Eastern Channel}

The Bayesian state-space two-stage biomass dynamics model provided a substantial contribution to the existing assessment method for the English Channel cuttlefish stock.

A Leslie-Delury depletion model was applied by Dunn (1999b) based on data from the UK beam trawl fleet only, but French landings were not taken into account in this model, although they are higher than English landings. Royer et al. (2006) have developed a monthly VPA, but the method could not be applied routinely because of the inconsistency of size structures.

The two-stage biomass model is an alternative for short-lived species with a lack of reliable age-data (Giannoulaki et al., 2014; Roel et al., 2009; Roel and Butterworth, 2000). In particular, the model developed in this study provides substantial extension to that developed by Gras et al. (2014) inter alia because it is developed in a state-space modelling framework that allows for a comprehensive integration of several sources of uncertainty in the biomass dynamics and in the data. The Bayesian framework also allows use of prior information on the biomass growth rate parameter. Finally, the flexibility of the state-space 
modelling framework allows us to easily expand the model and to test for the benefits of considering both $0+$ and $1+$ age groups in the biomass dynamics.

Model M1, based on a time-varying biomass growth rate and BTS, CGFS and LPUE time series and specific to group 1+ individuals, was found as the best trade-off between ecological significance, data requirement and transferability to other stocks, and is therefore the one we advocate for the English Channel cuttlefish stock.

The hypothesis of a time-invariant biomass growth rate parameter (model M2) was clearly rejected by our analysis because model M1 outperformed model M2 in terms of model fit, with a smaller DIC and a smaller NRMSE for the LPUE. This result is in accordance with published literature on cephalopods, which are known to experience high inter-annual growth variation (Challier, 2005; Domingues et al., 2006).

We found no clear advantages to including the $0+$ group in the model (model M3). Model M3 did not outperform M1 in terms of quality of fit, and including an additional 0+ group in the model required additional data and information that increased the sensitivity of model outputs. Hypotheses related to the prior distribution of the growth rate parameter $g_{0, y}$ can be questioned, as environmental variability might have a stronger impact on group 0 individuals than on group 1+ individuals. In fact, temperature and nutrient availability are known to affect both growth and natural mortality of cuttlefish, particularly during the juvenile phase (Moltschaniwskyj and Martinez, 1998). Calculation of growth of 0+ group might be biased because of micro-cohort issues. For example, Royer et al. (2006) indicates the presence of two micro-cohorts of cuttlefish in the English Channel, with a first recruitment around October, and a second around April. As the CGFS takes place in October, the mean growth calculated for group 0 animals might be biased for years when there were two micro-cohorts: only the first micro-cohort would be represented in the data of age class 0 in year $t$, whereas both micro-cohorts would be represented for age class 1 in year $t+1$.

Our model also illustrates the capacity of the framework to forecast biomass dynamics while propagating posterior uncertainty in forecasting. Model M4 provided predictions of the unexploited biomass in winter based on survey data, and could help manage the stock in the event of strong depletion.

\subsection{Limits of the approach}

The approach provides a framework for structuring further research and data collection. It is based on the assumption of a single population for the English Channel stock of cuttlefish. This assumption is supported by several authors (Dunn, 1999b; Le Goff and Daguzan, 1991; Pawson, 1995; Wang, 2003). However, stock boundaries are still not clearly defined and other research supports a substantial gene flow between the English Channel and the northern Northeast Atlantic (Gulf of Biscay, France) (Pérez-Losada et al., 2007). Wolfram et al. (2006) also showed there is an extensive gene flow among weakly structured cuttlefish populations from the Bay of Biscay into the North Sea. Investigating the spatial structure of cuttlefish populations in the Channel and Gulf of Biscay and its impact on stock assessment and management should form the basis for future research.

The results were sensitive to some of prior assumptions. Results from model M1 showed that $B_{2}$ and $g_{1, \mathrm{y}}$ were the most sensitive variables (Table 5). The sensitivity of the exploitation rate to the prior distribution of $g_{1, \mathrm{y}}$ was low, therefore this variable should be a good indicator of stock status, as proposed by Gras et al. (2014). Future research is needed to improve knowledge on the biomass growth rate and on the length-weight relationship. The method we developed to construct an informative prior on $g$ made use of data from Dunn (1999b) that ignores the variability over the years and within years of growth parameters. Future research should investigate the variation of the growth rate and length-weight relationship 
of cuttlefish, both over the years and within the years (e.g. through tag-recapture experiments).

\subsection{Management implications}

The estimates of exploitation rates differ noticeably from those of Gras et al. (2014). Specifically, Gras et al. (2014) did not detect any trend in exploitation rates between 1992 and 2008. Our study added six years of data, and estimated a decreasing trend of exploitation rate from 2001 to 2009.

Our model can be used to help define in-season assessment and management to limit the risk of overexploitation (Pierce and Guerra, 1994; Rosenberg et al., 1990). In France, the minimum landing weight of cuttlefish is $100 \mathrm{~g}$ and otter trawl nets are not allowed to use mesh size $<80 \mathrm{~mm}$. For pot fishery, there is also a limited number of fishing licenses. In Normandy, trawlers are allowed to fish cuttlefish spawners six weeks in spring inside 3 nautical miles as an exemption, which is decided each year around April. Another exemption allows them to target hatchlings for two weeks in the summer. Predictions of the unexploited biomass in winter $\left(B_{1 . j a n}\right)$ from model M4 could be used as information to authorize or alternatively to close those exemptions in the event of a very low biomass predicted for the fishing season.

\subsection{Applicability of the model to other stocks}

Beyond the case study of the English Channel cuttlefish stock, the approach provides general insights to improve cephalopod assessment models that can be transferred to other stocks of S. officinalis, in France or abroad, or even to other cephalopods species

Some European cuttlefish stocks monitored by the ICES Working Group on Cephalopod Fisheries and Life History have not been assessed. For most of them, data required for the two stage biomass dynamic model are available. An assessment of $S$. officinalis in the Bay of Biscay was conducted by Gi Jeon (1982), who used a VPA with a monthly time-scale and two age groups, based on data from years 1978-1979. A series of the French standardized LPUE can be calculated. Scientific data are available from Ifremer EVHOE survey (Evaluation of Fishing Resources in Western Europe), but the reliability of those data to construct an abundance index for cuttlefish abundance remains questionable because the survey occurs offshore in November, and therefore catches cuttlefish only if the migration has already happened.

Another stock of S. officinalis is found around Spain and Portugal. A time series of LPUE for Spanish trawlers is available, as well as a time series of survey abundance indices. The Moroccan Dakhla (2001-2006) stock, the Cape Blanc (1990-2006) stock in MauritaniaMorocco, and the Senegal-the Gambia stocks (1993-2006) have been assessed through a one stage Schaefer biomass production model (FAO/CECAF, 2007). As both catch and abundance indices from the survey and/or CPUE are available for all those $S$. officinalis stocks, developing a two-stage biomass model for those stocks would mean taking an interesting direction of research.

Other species of cuttlefish have been assessed (in India: Nair et al., 1993; Rao et al., 1993; off the Arabian Sea coast of Oman: Mehanna et al., 2014; and in the Gulf of Suez: Mehanna and Amin, 2005; Mehanna and El-Gammal, 2010). All these studies use lengthbased cohort analysis, which requires the very strong and not realistic assumption of a constant age-length relationship (Forsythe and Heukelem, 1987; Saville, 1987) and it could be worth developing more parsimonious two stage biomass models. 
Our results highlighted the key role of the informative priors on biomass growth rate parameters in the two stage model. Developing a meta-analysis to populate estimates of those parameters across many cuttlefish stocks (e.g., through hierarchical Bayesian models) could help improve the precision of informative priors and transfer information to stocks where only little information is available.

Some model assumptions should be tailored to fit some stock specificities. For stocks in warmer waters, we could expect a higher value of $G r$ (Richard, 1971). Cuttlefish experience a slower growth rate in the English Channel than in South Brittany, and a water temperature effect is suspected (Le Goff and Daguzan, 1991). The model presented here is developed under the assumption of an exclusive two-year life cycle which would no longer be valid. The model should be modified to take into account the co-existence of several reproduction strategies with various durations, as suggested for the Bay of Biscay stock that exhibit a mixture of 1 and 2 year life cycles.

\section{Acknowledgements}

We thank Michael Gras for actively answering questions about the initial model. We are also grateful to CEFAS for providing UK data. Special thanks to Beatriz Roel and Vladimir Laptikhovsky. French data come from DPMA, declarative data managed by Ifremer - SIH - Système d'Informations Halieutiques. Financial support for this work comes from Ifremer and from the "Conseil Régional de Normandie". We thank Pr. Andre Punt and an anonymous reviewer who gave their time and helped us enormously to improve this work. 


\section{References}

Archambault, B., Le Pape, O., Baulier, L., Vermard, Y., Véron, M., Rivot, E., 2016. Adultmediated connectivity affects inferences on population dynamics and stock assessment of nursery-dependent fish populations. Fish. Res. 181, 198-213. doi:10.1016/j.fishres.2016.03.023

Bettencourt, V., Guerra, A., 2001. Age studies based on daily growth increments in statoliths and growth lamellae in cuttlebone of cultured Sepia officinalis. Mar. Biol. 139, 327 334. doi:10.1007/s002270100582

Boucaud-Camou, E., Boismery, J., 1991. The migrations of the cuttlefish (Sepia officinalis L.) in the English Channel., in: The Cuttlefish, Université de Caen. Boucaud-Camou E., Caen, p. 179-189. 358 pp.

Brooks, S., Gelman, A., 1998. Some Issues for Monitoring Convergence of Iterative Simulations. Comput. Sci. Stat. 30-36.

Buckland, S.T., Newman, K.B., Fernández, C., Thomas, L., Harwood, J., 2007. Embedding Population Dynamics Models in Inference. Stat. Sci. 22, 44-58. doi:10.1214/088342306000000673

Caddy, J.F., 1996. Modelling natural mortality with age in short-lived invertebrate populations: definition of a strategy of gnomonic time division. Aquat. Living Resour. 9, 197-207.

Carpentier, A., Coppin, F., Curet, L., Dauvin, J.-C., Delavenne, J., Dewarumez, J.-M., Dupuis, L., Foveau, A., Garcia, C., Gardel, L., Harrop, S., Just, R., Koubbi, P., Lauria, V., Martin, C., Meaden, G., Morin, J., Ota, Y., Rostiaux, E., Smith, B., Spilmont, N., Vaz, S., Villanueva, C.-M., Verin, Y., Walton, J., Warembourg, C., 2009. Channel Habitat Atlas for marine Resource Management - CHARM II. URL http://archimer.ifremer.fr/doc/00000/7377/

Challier, L., 2005. Variabilité de la croissance des Céphalopodes juvéniles (Sepia officinalis, Loligo forbesi) et relation avec les fluctuations du recrutement, en Manche. University of Caen.

Coppin, F., Carpentier, A., Delpech, J.-P., Schlaich, I., 2002. Manuel des protocoles de campagne halieutique. Campagnes CGFS. V 3. URL http://archimer.ifremer.fr/doc/00036/14705/12011.pdf

Domingues, P.M., Bettencourt, V., Guerra, Á., 2006. Growth of Sepia officinalis in captivity and in nature. Vie Milieu 56, 109-120.

Dunn, M.R., 1999a. Aspects of the stock dynamics and exploitation of cuttlefish, Sepia officinalis (Linnaeus, 1758), in the English Channel. Fish. Res. 40, 277-293. doi:10.1016/S0165-7836(98)00223-9

Dunn, M.R., 1999b. The Exploitation of Selected Non-Quota Species in the English Channel $(\mathrm{PhD})$. University of Portsmouth.

Engelhard, G., Vignot, C., Leblond, M., Guitton, J., 2012. Atlas des pêcheries de Manche, Channel fisheries Atlas. Portail CHARM III - Interreg IV. [WWW Document]. URL http://charm-project.org/fr/outils/atlas-des-pecheries/atlas-des-pêcheries-outils

FAO/CECAF, 2007. Report of the FAO/CECAF Working Group on the Assessment of Demersal Resources-Subgroup North Banjul, the Gambia, 6-14 November 2007 (No. CECAF/ECAF SERIES 10/71). FAO/CECAF Working Group. URL http://www.fao.org/docrep/015/i2545b/i2545b00.pdf

Fletcher, D., Mackenzie, D., Villouta, E., 2005. Modelling skewed data with many zeros: A simple approach combining ordinary and logistic regression. Environ. Ecol. Stat. 12, $45-54$.

Forsythe, J.W., Heukelem, W.F., 1987. Growth, in: Cephalopod Life Cycles, Comparative Reviews. P.R. Boyle, London, pp. 135-156. 
Gelman, A. (Ed.), 2004. Bayesian data analysis, 2nd ed. ed, Texts in statistical science. Chapman \& Hall/CRC, Boca Raton, Fla.

Gelman, A., Carlin, J.B., Stern, H.S., Dunson, D.B., Vehtari, A., Rubin, D.B., 2014. Bayesian data analysis, Third edition. ed, Chapman \& Hall/CRC texts in statistical science. CRC Press, Boca Raton.

Gi Jeon, I., 1982. Etude de populations de seiches (Sepia officinalis Linné) du golfe de Gascogne.

Giannoulaki, M., Ibaibarriaga, L., Antonakakis, K., Uriarte, A., Machias, A., Somarakis, S., Sanchez, S., Roel, B.A., 2014. Applying a two-stage Bayesian dynamic model to a short lived species, the anchovy in the Aegean Sea (Eastern Mediterranean). Comparison with an Integrated Catch at Age stock assessment model. Mediterr. Mar. Sci. 15, 350-365.

González, A.F., Dawe, E.G., Beck, P.C., Perez, J.A.A., 2000. Bias associated with statolithbased methodologies for ageing squid; a comparative study on Illex illecebrosus (Cephalopoda: Ommastrephidae). J. Exp. Mar. Biol. Ecol. 244, 161-180. doi:10.1016/S0022-0981(99)00136-7

Gras, M., Roel, B.A., Coppin, F., Foucher, E., Robin, J.-P., 2014. A two-stage biomass model to assess the English Channel cuttlefish (Sepia officinalis L.) stock. ICES J. Mar. Sci. J. Cons. 71, 2457-2468. doi:10.1093/icesjms/fsu081

Hanley, J.S., Shashar, N., Smolowitz, R., Bullis, R.A., Mebane, W.N., Gabr, H.R., Hanlon, R.T., 1998. Modified laboratory culture techniques for the European cuttlefish Sepia officinalis. Biol. Bull. 223-225.

Hilborn, R., Liermann, M., 1998. Standing on the shoulders of giants: learning from experience in fisheries. Rev. Fish Biol. Fish. 8, 273-283.

Le Goff, R., Daguzan, J., 1991. Growth and life cycles of the cuttlefish Sepia officinalis L. (Mollusca: Cephalopoda) in South Brittany (France). Bull. Mar. Sci. 49, 341-348.

Lipinski, M.R., Durholtz, M.D., Underhill, L.G., 1998. Field validation of age readings from the statoliths of chokka squid (Loligo vulgaris reynaudii d'Orbigny, 1845) and an assessment of associated errors. ICES J. Mar. Sci. J. Cons. 55, 240-257.

Lo, N.C., Jacobson, L.D., Squire, J.L., 1992. Indices of relative abundance from fish spotter data based on Delta-Lognornial Models. Can. J. Fish. Aquat. Sci. 49, 2515-2526.

Lunn, D., Spiegelhalter, D., Thomas, A., Best, N. 2009. The BUGS project: Evolution, critique and future direction. Statistics in Medecine, 28, 3049-3067.

Macdonald, P., Du, J., Macdonald, M.P., 2011. Package "mixdist." Finite Mix. Distrib. Models V0 5-4.

Mangold-Wirz, K., 1963. Biologie des céphalopodes benthiques et nectoniques de la Mer Catalane. Laboratoire Arago.

Medhioub, A., 1986. Etude de la croissance et la maturation sexuelle de la population de seiche des côtes normandes. Université de Caen, Caen, France.

Mehanna, S.F., Al-Kharusi, L., Al-Habsi, S., 2014. Population dynamics of the pharaoh cuttlefish Sepia pharaonis (Mollusca: Cephalopoda) in the Arabian Sea coast of Oman. Indian J. Fish. 61, 7-11.

Mehanna, S.F., Amin, A.M., 2005. Population dynamics of the cuttlefish Sepia dollfusi (Adam, 1941) from the Gulf of Suez, Egypt. Egyp J Aquat Biol Fish 9, 1-14.

Mehanna, S.F., El-Gammal, F.I., 2010. Growth and population dynamics of the cuttlefish Sepia savignyi Blainville in the Gulf of Suez, Red Sea. Indian J. Fish. 57, 1-6.

Moltschaniwskyj, N.A., Martinez, P., 1998. Effect of temperature and food levels on the growth and condition of juvenile Sepia elliptica (Hoyle 1885): an experimental approach. J. Exp. Mar. Biol. Ecol. 229, 289-302. doi:10.1016/S00220981(98)00058-6 
Nair, K.P., Srinath, M., Meiyappan, M.M., Rao, K.S., Sarvesan, R., Vidyasagar, K., Sundaram, K.S., Rao, G.S., Lipton, A.P., Natarajan, P., others, 1993. Stock assessment of the pharaoh cuttlefish Sepia pharaonis. Indian J. Fish. 40, 85-94.

Parent, E., Rivot, E., 2013. Introduction to hierarchical Bayesian modeling for ecological data, Chapman \& Hall/CRC applied environmental statistics. CRC Press, Boca Raton.

Pawson, M.G., 1995. Biogeographical identification of English Channel fish and shellfish stocks (No. 99), Fish. Res. Tech. Rep. MAFF Direct. Fish. Res., Lowestoft.

Pérez-Losada, M., Nolte, M.J., Crandall, K.A., Shaw, P.W., 2007. Testing hypotheses of population structuring in the Northeast Atlantic Ocean and Mediterranean Sea using the common cuttlefish Sepia officinalis. Mol. Ecol. 16, 2667-2679. doi:10.1111/j.1365-294X.2007.03333.x

Pierce, G.J., Allcock, L., Bruno, I., Bustamante, P., González, A., Guerra, A., Jereb, P., Lefkaditou, E., Malham, S., Moreno, A., others, 2010. Cephalopod biology and fisheries in Europe, ICES Cooperative Research Report No. 303. ICES.

Pierce, G.J., Guerra, A., 1994. Stock assessment methods used for cephalopod fisheries. Fish. Res. 21, 255-285.

Rao, K.S., Srinath, M., Meiyappan, M.M., Nair, K.P., Sarvesan, R., Rao, G.S., Natarajan, P., Vidyasagar, K., Sundaram, K.S., Lipton, A.P., Radhakrishnan, G., Narasimha, K.A., Mohamed, K.S., Balan, K., Kripa, V., Sathianandan, T.V., 1993. Stock assessment of the needle cuttlefish Sepia aculeata Orbigny. Indian J. Fish. 40, 95103.

Richard, A., 1971. Contribution à l'étude expérimentale de la croissance et de la maturation sexuelle de Sepia officinalis L. (Mollusque Céphalopode) (PhD). University of Lille I.

Rivot, E., Prévost, E., Parent, E., Baglinière, J.L., 2004. A Bayesian state-space modelling framework for fitting a salmon stage-structured population dynamic model to multiple time series of field data. Ecol. Model. 179, 463-485. doi:10.1016/j.ecolmodel.2004.05.011

Rodhouse, P.G.K., Pierce, G.J., Nichols, O.C., Sauer, W.H.H., Arkhipkin, A.I., Laptikhovsky, V.V., Lipiński, M.R., Ramos, J.E., Gras, M., Kidokoro, H., Sadayasu, K., Pereira, J., Lefkaditou, E., Pita, C., Gasalla, M., Haimovici, M., Sakai, M., Downey, N., 2014. Environmental effects on cephalopod population dynamics: implications for management of fisheries. Adv. Mar. Biol. 67, 99-233. doi:10.1016/B978-0-12-800287-2.00002-0

Roel, B.A., Butterworth, D.S., 2000. Assessment of the South African chokka squid Loligo vulgaris reynaudii - Is disturbance of aggregations by the recent jig fishery having a negative impact on recruitment? Fish. Res. 48, 213-228. doi:10.1016/S01657836(00)00186-7

Roel, B.A., De Oliveira, J.A.A., Beggs, S., 2009. A two-stage biomass model for Irish Sea herring allowing for additional variance in the recruitment index caused by mixing of stocks. ICES J. Mar. Sci. J. Cons. 1808-1813. doi:10.1093/icesjms/fsp144

Rosenberg, A.A., Kirkwood, G.P., Crombie, J.A., Beddington, J.R., 1990. The assessment of stocks of annual squid species. Fish. Res. 8, 335-350. doi:10.1016/01657836(90)90003-E

Royer, J., Pierce, G.J., Foucher, E., Robin, J.P., 2006. The English Channel stock of Sepia officinalis: Modelling variability in abundance and impact of the fishery. Fish. Res. 78, 96-106. doi:10.1016/j.fishres.2005.12.004 
Saville, A., 1987. Comparisons between cephalopods and fish of those aspects of the biology related to stock management, in: Cephalopod Life Cycles, Comparative Reviews. P.R. Boyle, London, pp. 277-290.

Spiegelhalter, D.J., Best, N.G., Carlin, B.P., Van Der Linde, A., 2002. Bayesian measures of model complexity and fit. J. R. Stat. Soc. Ser. B Stat. Methodol. 64, 583-639.

Stefansson, G., 1996. Analysis of groundfish survey abundance data: combining the GLM and delta approaches. ICES J. Mar. Sci. 53, 577-588. doi:10.1006/jmsc.1996.0079

Wang, J., 2003. Spatial and temporal patterns of cuttlefish (Sepia officinalis) abundance and environmental influences - a case study using trawl fishery data in French Atlantic coastal, English Channel, and adjacent waters. ICES J. Mar. Sci. 60, 1149-1158. doi:10.1016/S1054-3139(03)00118-8

Wolfram, K., Mark, F.C., John, U., Lucassen, M., Pörtner, H.O., 2006. Microsatellite DNA variation indicates low levels of genetic differentiation among cuttlefish (Sepia officinalis L.) populations in the English Channel and the Bay of Biscay. Comp. Biochem. Physiol. Part D Genomics Proteomics 1, 375-83. doi:10.1016/j.cbd.2006.08.003 


\section{Appendix A}

We applied the package mixdist (Macdonald et al., 2011) to length frequency data obtained from the French Onboard Observer Program (Obsmer) to calculate the individual growth rate for group $1+$ individuals $\left(G r_{1+}\right)$. This program aims to collect catch data onboard commercial fishing vessels. External observers follow a specified sampling scheme and collect data on fish kept on board and discarded fish. The number of cuttlefish sampled each year is given in Table A.1. The mean length of group 1+ individuals was calculated in October and December, as the cohort split-up is of better quality for these months. The Dunn (1999a) length-weight relationship was used to convert mean length into mean weight $\left(\bar{w}_{1+}\right)$. The variability of mean weight values is plotted on Fig. A.1. The goodness-of-fit of the chisquare statistic was checked, and the fishing seasons where one of the cohort split-up model has a $p$-value above 0.05 were not used in the growth rate calculation.

For each fishing season where the cohort split-up is reliable, annual growth coefficients $\mathrm{Gr}_{\mathrm{y} 1+}$ were calculated using Eqn A1, then $\mathrm{Gr}_{1+}$ was calculated as the median value of all $\mathrm{Gr}_{\mathrm{y} 1+}$.

$$
G r_{y 1+}=\log \left(\bar{w}_{1+, \text { December }} / \bar{w}_{1+, \text { october }}\right) * 6
$$

To calculate the mean growth coefficient for group 0 individuals $\left(\mathrm{Gr}_{0}\right)$ we used the package mixdist on length frequency data from CGFS survey:

$$
G r_{y 0}=\log \left(\bar{w}_{1, y+1} / \bar{w}_{0, y}\right)
$$

where $\bar{w}_{0, y}$ is the mean weight of group 0 individuals in year $y$ and $\bar{w}_{1, y+1}$ is the mean weight of group 1+ individuals in the following fishing season. $G r_{0}$ was calculated as the median value of all $G r_{\mathrm{y} 0}$.

CGFS data from 2006 to 2014 were used. Length data obtained from the mixdist package had an inter-year CV of 0.14 for age 0 and 0.065 for age 1. To calculate the mean growth coefficient of group 1+ individuals $\left(G r_{1+}\right)$, Obsmer data were used (Table A.1). Cohort splitup was reliable for seven years from 2005 to 2014 (Fig. A.1). Length data obtained from the mixdist package had an inter-year CV of 0.058 in October and 0.054 in December. A CV value of 0.1 was used to construct the parameters $\mu_{g 0}$ and $\mu_{g 1}$, used as mean values for the construction of the priors for $g_{0, \mathrm{y}}$ and $g_{1, \mathrm{y}}$ (Table 1). We found a value of 2.816 for $G r_{0}$ and a value of 1.542 for $\mathrm{Gr}_{1+}$, with inter-year CVs of 0.13 and 0.64 respectively.

Natural mortality $(M)$ was calculated using the Caddy (1996) gnomonic time division method. This method assumes that $M$ is a simple function of mean lifespan and is constant. A vector of natural mortality-at-age is calculated: the life-span is divided into several intervals whose duration increases proportionally to the age, and natural mortality is assumed to be constant for each interval. The time-division is called gnomonic, and for each interval, a constant number $(\beta)$ is obtained when multiplying the instantaneous mortality rate by the interval duration. The initial death rate is assumed to be high, and after a few months, a plateau is obtained. An initial number of individuals must be chosen, and exactly 2 survivors must remain after 2 years to ensure population replacement.

The mortality function was fitted with an initial number of hatchlings $\left(N_{1}\right)$ derived from fecundity estimates. Previous studies on cuttlefish fecundity were used to choose values for the initial number of individuals. Mangold-Wirz (1963) reported that females Sepia officinalis may spawn from about 150 to 4,000 eggs depending on their size. Richard (1971) estimated numbers of 150 to 500 eggs by counting mature ova only, and a mean number of 2,000 eggs was observed in laboratory culture (Hanley et al., 1998). Four values of $\mathrm{N}_{1}$ are tested: 500, 1,000, 1,500 and 2,000. 
The two years life span is divided into a number $i$ of smaller time intervals $\Delta_{i}$. A value of $2 / 365$ is set for the first interval $\Delta_{1}$. For each interval:

$$
N_{i+1}=N_{i} * \exp \left(-M_{i} * \Delta_{i}\right)
$$

where $M_{i}$ is the mortality rate for the interval of duration $\Delta_{i}$.

$$
M_{i} * \Delta_{i}=\beta
$$

where $\beta$ is a constant.

To create a series of intervals of increasing duration starting at $t=0$, given a first time interval $\Delta_{1}=t_{1}$, we multiply the time elapsed to the start of each new interval by a constant multiplier, $\alpha$ (Caddy, 1996).

$$
t_{n}=\sum_{i=1}^{n} \Delta_{i}, \quad \text { where } \Delta_{i}=\alpha * t_{i-1} \quad(i \geq 2)
$$
2.

Parameters $\alpha$ and $\beta$ were calculated using iterations to achieve $\sum_{i=1}^{n} \Delta_{i}=2$ and $N_{n}=$

To estimate the natural mortality of group $1+$ individuals $\left(M_{1+}\right)$, we set the number of time intervals such that the last time interval ends at $t=2$ years and lasts approximately 12 months. After the division of the lifespan into 10 gnomonic time intervals, we calculated the decline in numbers such that exactly 2 spawners survive by two years of age. To estimate the natural mortality of group 0 individuals $\left(M_{0}\right)$, we calculated the mean mortality value of the $8^{\text {th }}$ and $9^{\text {th }}$ intervals, which matches the period when animals are between 3 months and 12 months old. We tested four possible values for the initial number of individuals $\left(N_{1}\right)$ for 10 gnomonic time-intervals (Table A.2). With 10 time-intervals, the pre-spawning interval was 11.5 months, so the resulting mortality was related to group $1+$ individuals. Once the values of individual growth and natural mortality were calculated, we could obtain Grand mean $\mu_{\mathrm{g} 0}$ and Grand mean $\mu_{\mathrm{g} 1}$, used for the construction of $\mu_{\mathrm{g} 0}$ and $\mu_{\mathrm{g} 1}$ (Table A.3).

Table A.1

Number of individuals sampled in Obsmer and CGFS. “*” indicates years that were not used for growth rate calculation because one cohort split-up of this year was not reliable.

\begin{tabular}{ccc|cc}
\hline & Obsmer & & \multicolumn{2}{c}{ CGFS } \\
\hline Year & October & December & Year & October \\
\hline 2005 & 277 & 252 & 2005 & 341 \\
2006 & 1035 & 186 & 2006 & 344 \\
$2007^{*}$ & 245 & 138 & 2007 & 157 \\
2008 & 409 & 220 & 2008 & 110 \\
2009 & 526 & 161 & 2009 & 146 \\
$2010^{*}$ & 1304 & 220 & 2010 & 147 \\
$2011^{*}$ & 655 & 153 & 2011 & 81 \\
2012 & 755 & 796 & 2012 & 161 \\
2013 & 1035 & 334 & 2013 & 131 \\
2014 & 1001 & 1488 & 2014 & 140 \\
\hline
\end{tabular}




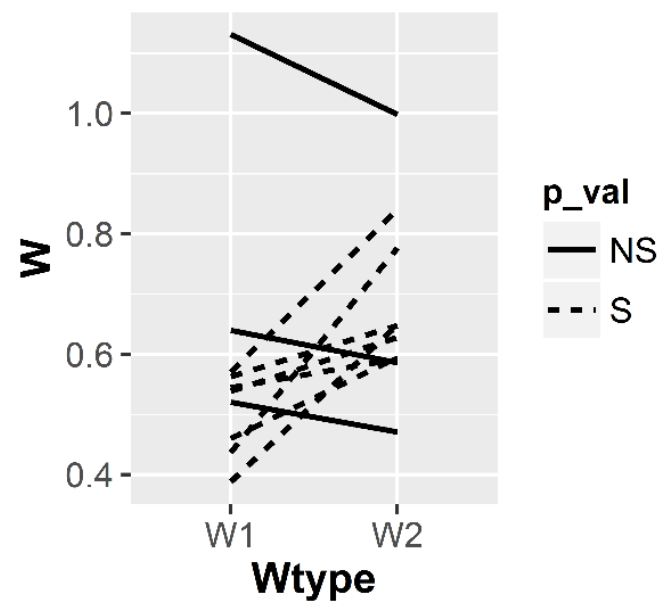

Fig. A.1. The variability of mean weight values of group 1+ individuals after cohort split-up of Obsmer length data. W1 is the mean weight in October and W2 is the mean weight in December. Full lines represent the years where $p$-value of cohort split-up model was not significant (NS). Dotted lines represent the years where $p$-value of cohort split-up model was significant (S) and therefore used for growth rate calculation.

Table A.2

Estimates natural mortality for different values of $N_{1}$ and different pre-spawning intervals.

\begin{tabular}{lllllll}
\hline $\mathbf{N}_{1}$ & $\mathbf{a}$ & $\boldsymbol{\beta}$ & $\begin{array}{l}\mathbf{M} \text { (group } \\
\mathbf{0}\end{array}$ & $\begin{array}{l}\mathbf{M} \\
\text { (group 1+) }\end{array}$ & $\begin{array}{l}\text { Pre-spawning } \\
\text { interval (months) }\end{array}$ & $\begin{array}{l}\text { Number of gnomonic } \\
\text { time-intervals }\end{array}$ \\
\hline 500 & 0.926 & 0.552 & 1.618 & 0.574 & 11.5 & 10 \\
1000 & 0.926 & 0.621 & 1.821 & 0.646 & 11.5 & 10 \\
1500 & 0.926 & 0.662 & 1.94 & 0.688 & 11.5 & 10 \\
2000 & 0.926 & 0.691 & 2.024 & 0.718 & 11.5 & 10 \\
\hline
\end{tabular}

Table A.3

Summary of natural mortality, mean growth coefficient and $g$ parameter.

\begin{tabular}{cccc}
\hline Age class & Mean mortality & Mean individual growth & Mean biomass growth \\
\hline 0 & 1.851 & 2.816 & Grand mean $\mu_{\mathrm{g} 0}=0.97$ \\
$1+$ & 0.657 & 1.542 & Grand mean $\mu_{\mathrm{g} 1}=0.89$ \\
\hline
\end{tabular}




\section{Appendix B}

To calculate the French LPUE used in this work, we first separated out the catch into two age groups 0 and $1+$ for each year and month. Four variables were used in the statistical model to explain the variability of the LPUE: fishing season $y$, month $m$, ICES rectangle $r$ and the engine power of the vessel $p$. No interactions were taken into account. For the engine power, the values were classified into 13 modalities. In the following, $U_{y, m, r, p}^{l p u e{ }_{1} \text { obs }}$ denotes the LPUE abundance indices observed for fishing season $y$, month $m$, ICES rectangle $r$ and engine power modality $p$. To calculate $U_{y, m, r, p}^{l p u e 1_{1} o b s}$, the catches of group $1+$ individuals in kilograms were divided by the effort in number of fishing hours.

We present only the equations related to the calculation of the LPUE time series of group $1+$ individuals. The same method was applied for group 0 animals. To account for zeroinflation in the data, a binomial error GLM (Eqn B1) and a Gaussian error GLM on positive values (Eqn B2) were developed separately and then combined to provide model estimates of the abundance. Standardized abundance indices $U_{y, m, r, p}^{l p u e 1_{s} s t}$ were calculated for each fishing season, month, ICES rectangle and vessel power modality as the probability of positive observations multiplied by the expected catch rate conditional to the observations being positive (Eqn B3).

The binomial GLM model on presence-absence data:

$$
\operatorname{logit}\left(U_{y, m, r, p}^{\text {lpue } 1_{1} \text { obs }}\right)_{0 / 1}=\alpha_{y}+\beta_{m}+\gamma_{r}+\delta_{p}+\omega_{y, m, r, p}
$$

The log-gaussian GLM model on positive data:

$$
\operatorname{Ln}\left(U_{y, m, r, p}^{l p u e 1_{i} o b s}\right)_{>0}=\operatorname{Ln}\left(\alpha_{y}\right)+\operatorname{Ln}\left(\beta_{m}\right)+\operatorname{Ln}\left(\gamma_{r}\right)+\operatorname{Ln}\left(\delta_{p}\right)+\varepsilon_{y, m, r, p}
$$

The prediction of abundance indices based on the combination of the two models:

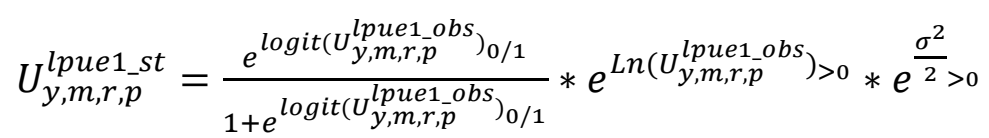

where $\omega_{y, m, r, p}$ and $\varepsilon_{y, m, r, p}$ are the residuals for fishing season $y$, month $m$, ICES rectangle $r$ and engine power modality $p . \sigma$ is the standard error of the Gaussian error GLM.

The standardized re-scaled LPUE $U_{y}^{l p u e 1}$ was calculated for each fishing season as the average on all predicted values divided by the first value of the time series:

$$
U_{y}^{l p u e 1}=\frac{\sum_{m, p, r} U_{y, m, p, r}^{\text {lpue } 1 \text { st }} / N^{m, p, r} y}{U_{1}^{l p u e 1}}
$$

where $N_{y, p, r}$ is the number of predicted values for each fishing season. 